\title{
Numerical and Experimental Transition Results Evaluation for a Morphing Wing and Aileron System
}

\author{
Ruxandra Mihaela Botez, Andreea Koreanschi, Oliviu Sugar Gabor \\ Research Laboratory in Active Control, Avionics and AeroServoElasticity \\ (LARCASE) \\ Ecole de Technologie Superieure, Montreal \\ Youssef Mebarki, Mahmoud Mamou \\ The Aerodynamics Laboratory, NRC Aerospace \\ Ottawa, \\ Canada \\ Yvan Tondji, Mohamed Guezguez, Joel Tchatchueng Kammegne, Lucian Teodor Grigorie, Dragos Sandu \\ Research Laboratory in Active Control, Avionics and AeroServoElasticity \\ (LARCASE) \\ Ecole de Technologie Superieure, Montreal \\ Francesco Amoroso, Rosario Pecora, Leonardo Lecce \\ University of Naples "Federico II", \\ Industrial Engineering Dept. - Aerospace Division, Naples, Italy \\ Gianluca Amendola, Ignazio Dimino, Antonio Concilio \\ The Italian Aerospace Research Center \\ (CIRA) \\ Adaptive Structure Division, Capua (CE), Italy
}

\begin{abstract}
A new wing-tip concept with morphing upper surface and interchangeable conventional and morphing ailerons was designed, manufactured, bench and wind tunnel tested. The development of this wing tip model was performed in the frame of an international CRIAQ project, and the purpose was to demonstrate the wing upper surface and aileron morphing capabilities in improving the wing tip aerodynamic performances. During numerical optimization with 'in-house' genetic algorithm software, and during wind tunnel experimental tests, it was demonstrated that the air flow laminarity over the wing skin was promoted, and the laminar flow was extended with up to $9 \%$ of the chord. Drag coefficient reduction of up to $9 \%$ was obtained when the morphing aileron was introduced.
\end{abstract}




\section{Acronym List}

CFD - Computational Fluid Dynamics

CIRA - Italian Center for Research in Aerospace

CRIAQ - Consortium for Research and Innovation in

Aerospace in Quebec

CRNC - Canadian National Research Council

ETS - Ecole de Technologie Superieure

MDO - Multi Disciplinary Objective

IR - Infrared thermography

UAV/UAS - unmanned aerial vehicle/system

\section{Nomenclature List}

\author{
$\lambda$ - laminar to transition flow boundary parameter \\ $\mathrm{C}_{\mathrm{i}}$ - case number $\mathrm{i}$ \\ $\mathrm{C}_{\mathrm{d}}-$ drag coefficient \\ $\mathrm{C}_{1}$ - lift coefficient \\ $\mathrm{C}_{\mathrm{p}}$ - pressure coefficient \\ Count $-1 \mathrm{e}^{-3}$ \\ $\mathrm{F}_{\mathrm{f}}-$ Fitness function \\ $\gamma$ - Intermittency variable \\ $\tau$ - Transition to turbulent flow boundary parameter \\ Re - Reynolds number \\ $\mathrm{Tr}_{\text {error }}-$ Absolute transition error \\ $\mathrm{Up}_{\mathrm{Tr}}-$ Upper surface transition \\ $\mathrm{W}_{\mathrm{i}}$ - fitness function weight \\ $\mathrm{x} / \mathrm{c}-$ chord distribution \\ $\mathrm{y}+$ - wall condition
}

\section{Introduction}

The air transportation industry is a key contributor to economic development around the world. Since the beginning of civil aviation, there has been a steady increase in the number of passengers using airplanes as a fast and safe transportation method, with airlines carrying almost three billion passengers worldwide in 2014 alone. This achievement has also transformed the air transport industry into a non-negligible source of pollution. In 2014, over $2 \%$ of the worldwide carbon dioxide emissions were attributed to commercial airline companies ${ }^{1}$.

Today, researchers compete to find the best solutions to be applied to solve the emission problem, both on long and short terms. One such solution is the morphing of the aircraft. Aircraft morphing is not a new concept, as it was applied by the military aviation on some of their more renowned aircrafts, such as the Grumann F-14 ${ }^{2}$, the North American Aviation XB-70 Valkyrie prototype ${ }^{3}$ and the AFTI/F-111 'Mission Adaptive Wing' ${ }^{4}$. Recently, the concept of aircraft morphing started being researched for civil and unmanned aviation as well.

A morphing wing could allow the aircraft to fly at optimal lift-to-drag ratios for any condition encountered during flight by changing some of its wing characteristics. Researchers have proposed different technological solutions for obtaining the desired wing adaptability, and some of the concepts have achieved important theoretical performance improvements compared to the baseline design. However, the technology is still in the early stages of development, its technological readiness level is still low, and only a few concepts have sufficiently progressed to reach wind tunnel testing, and even fewer have actually been flight tested.

For the Unmanned Aerial Vehicles, research was conducted by many teams. Some of the most interesting morphing applications were described by Sofla et $a l^{5}$ and Barbarino et $a l^{6}$ in their literature review papers. Interesting research on the effect of morphing of the UAV and UAS wing related to their aerodynamic performances was conducted by Sugar. $\mathrm{O}$ et al ${ }^{7 \text { and } 8}$.

Pecora et al. ${ }^{9}$ demonstrated the effectiveness of replacing the conventional segmented flap with a morphing compliant high-lift device, in the case of a regional transport aircraft. Bilgen et al. ${ }^{10 \text { and } 11}$ also presented the concept of replacing the wing trailing-edge devices with a morphing surface, capable of achieving continuous camber variations instead of rigid deflections. The morphing system was designed to replace the ailerons of an UAV, for which it used rapid, electrical actuation mechanisms. Both wind tunnel experiments and preliminary flight test were performed, and demonstrated the effectiveness of the concept at providing accurate roll control. Pankonien and Inman ${ }^{12}$ presented a concept for morphing ailerons designed to replace the conventional wing control surfaces of an UAV. The aerodynamic performance of the system was evaluated using wing tunnel testing. The experimental measurements focused on the drag coefficient penalties associated with classic control surface deflections at offdesign flight conditions. The use of the morphing trailing edge achieved drag reductions of up to $20 \%$ compared to its original design, thus justifying its increased mass and complexity.

A project that was dedicated to developing a new concept of morphing wing for civil aviation was the CRIAQ 7.1 project ${ }^{13,14}$. This project was developed under partnership between Bombardier Aerospace, Thales Avionics 
Canada, Ecole de Technologie Superieure, Ecole Polytechnique and the Canadian National Research Council (CNRC). The purpose of the project was the development of a wing model capable of deforming its upper surface using controlled movement of two lines of shape memory alloy actuators installed on the upper surface skin ${ }^{15}$ and 16 . The morphing upper surface skin itself was developed through optimization techniques as Carbon-Kevlar composite. The model's capabilities were tested at the CNRC subsonic wind tunnel in Ottawa, and the objective of the tests was to observe the behavior of the flow transition with the aim to delay it. The results have shown that the wing model achieved high transition delays and the balance measurements have read drag coefficient reductions of up to $20 \%{ }^{17}$. A subsequent aeroelastic study proved that the morphing technique would not induce flutter phenomena during wind tunnel testing ${ }^{18}$. In addition, many breakthroughs were achieved in active open-loop ${ }^{19}$ and closed-loop ${ }^{20}$ control using PID ${ }^{21}$, fuzzy logic and neural network controllers in wind tunnel testing ${ }^{22}$ and 23 under the auspices of this same project.

The research presented in this paper was conducted in the frame of the CRIAQ MDO 505 project 'Morphing Architectures and Related Technologies for Wing Efficiency Improvement'. This project was an international collaboration between Canadian and Italian industry, academic and research teams. The Canadian partners were Bombardier Aerospace, Thales Canada, Ecole de Technologie Superieure (ETS), Canadian National Research Council (CNRC) and Ecole Politechnique. The Italian partners were Alenia Aermacchi, the University of Naples Federico II (UNINA) and the Italian Center for Research in Aerospace (CIRA). The purpose of the project was to develop a full-size wing tip structure equipped with a morphing upper surface and two types of ailerons: a conventional rigid aileron and a morphing aileron. The objective of the development of such a wing-tip was threefold: 1) through upper surface morphing and aileron morphing change the shape of the wing and influence its aerodynamic performances towards delay of the transition of the flow between laminar and turbulent states; 2) through optimization of the structure and of the upper surface composite skin, maintain a wing structure that respects structural requirements for certification and remains similar to a real aircraft wing tip structure ${ }^{24}$ and 25 ; and 3 ) demonstrate that an integrated control system for the morphing upper surface and ailerons can achieve the desired shapes obtained during numerical optimization ${ }^{26}$ and 27.

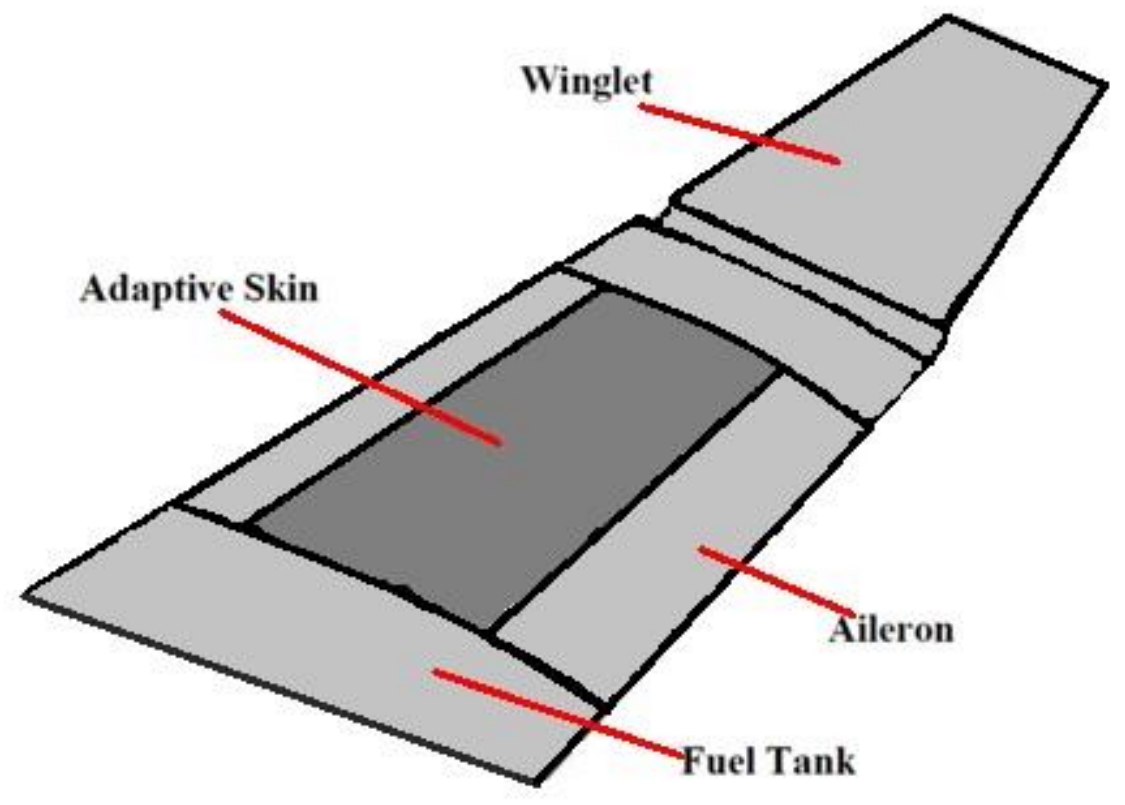

Figure 1 The layout of the morphing skin on the aircraft wing 


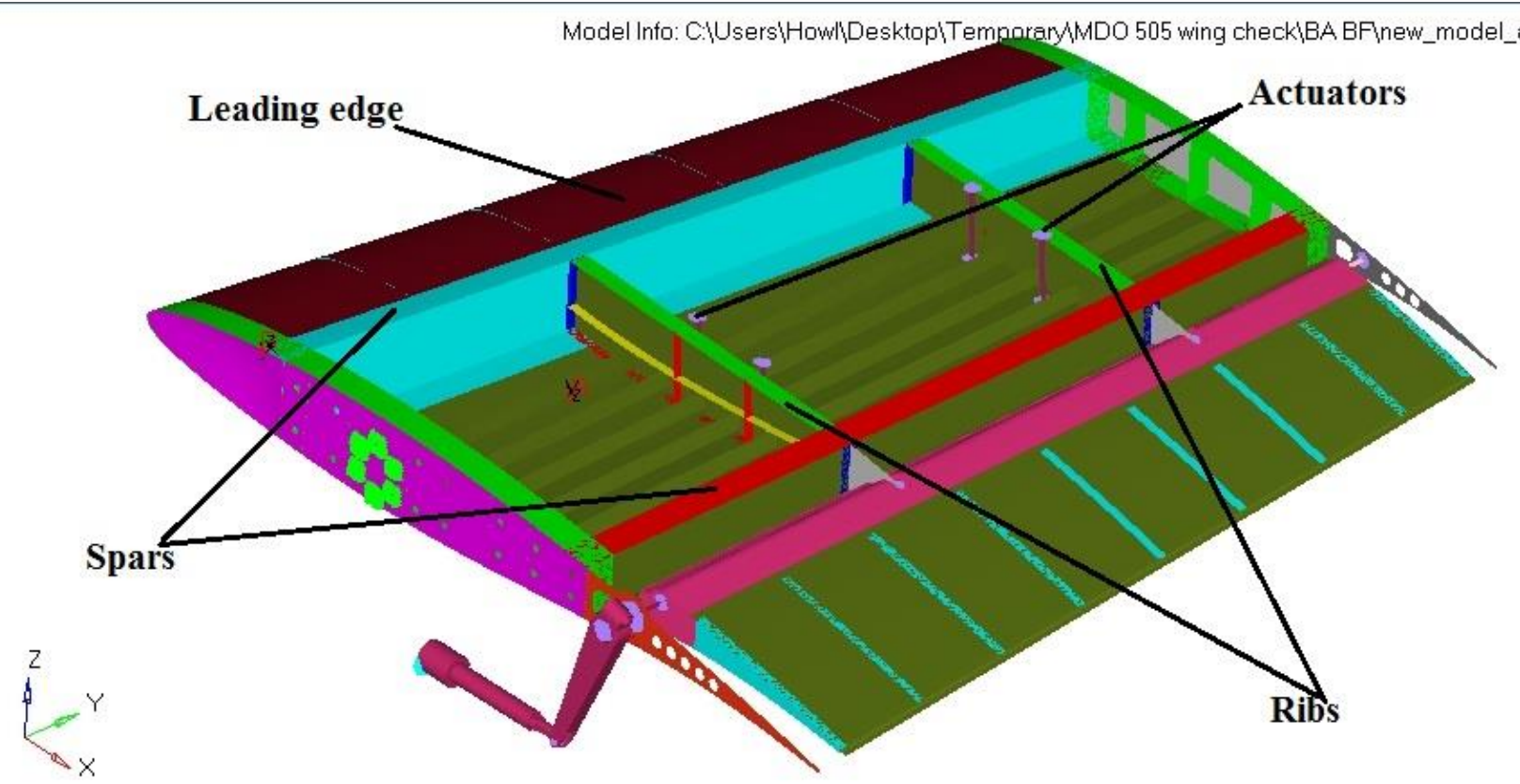

Figure 2 The structural elements of the CRIAQ MDO 505 morphing wing box (the morphing skin is not shown in the figure)

\section{General Details on the Morphing Wing Model}

The full-scale morphing wing model is a structure with a $1.5 \mathrm{~m}$ span and a $1.5 \mathrm{~m}$ root chord, a taper ratio of 0.72 , and leading and trailing edges sweep angles of $8^{\circ}$. The chord distribution of the wing model follows the one of the real wing-tip section, while the sweep angle and the spanwise twist distribution were modified (smaller twist and sweep angle) in order to reduce the structure's complexity and to obtain a more flat surface between the ribs to better observe and measure the upper surface deformation. The wing box and its internal structure (spars, ribs, and lower skin) were manufactured from aluminum alloy material, while the adaptive upper surface, which was positioned between $20 \%$ and $65 \%$ of the wing chord, was manufactured using carbon fibre composite materials ${ }^{28}$.

The deformation of skin shape, driven by actuators placed inside the wing box structure, is a function of the flight condition (defined in terms of Mach number, Reynolds number and angle of attack). These actuators were specifically designed and manufactured to meet the project requirements. Four electrical actuators were installed on two actuation lines; two actuators each, placed at $37 \%$ and $75 \%$ of the wing span, were fixed to the ribs and to the composite skin. Each actuator has the ability to operate independently from the others, and has a displacement range between $\pm 3.5 \mathrm{~mm}$. On each actuation line, the actuators were positioned at $32 \%$ and $48 \%$ of the local wing chord. The aileron hinge articulation was located at $72 \%$ of the chord. Two ailerons were designed and manufactured. One aileron was structurally rigid, while the other one represented a new morphing aileron concept. Both ailerons were designed to be attached to the same hinge axis of the wing box, and both are able to undergo a controlled deflection between $-7^{\circ}$ and $+7^{\circ}$. This interval was more restricted than the normal deflection range of an aileron, but it was considered sufficient to demonstrate the proof of concept for the morphing aileron. This restriction was determined by the available space inside the NRC wind tunnel and by the load limits of the wind tunnel balance. Figure 3 presents the morphing wing model concept as it would be mounted and tested in the NRC subsonic wind tunnel. 


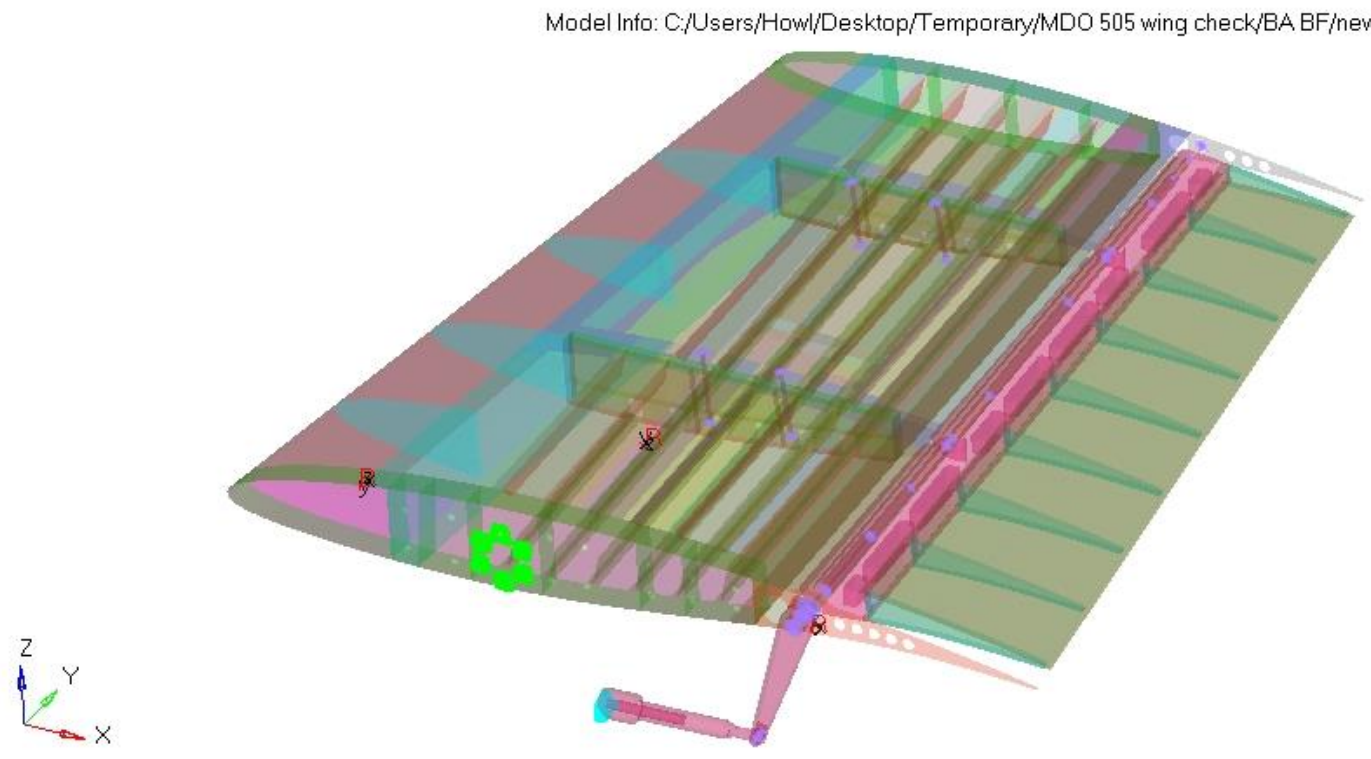

Figure 3 CRIAQ MDO 505 morphing wing model

The control of the actuators was realized with four various controllers - PID, Fuzzy Logic and two Neural Network methods - that were integrated with the measurement systems incorporated into the model. Figure 4 presents an overview of the morphing wing control system.

The wing was equipped with 32 kulite pressure sensors installed on two parallel staggered lines at $60 \mathrm{~cm}$ from the root of the wing. Three accelerometers were installed on the wing: one each on the wing box, aileron and balance shaft, for safety purposes, by monitoring the vibration behaviour of the wing during wind tunnel tests.

The wing tip was manufactured at NRC and ETS, and complied with the technological requirements demanded by the industrial partners.

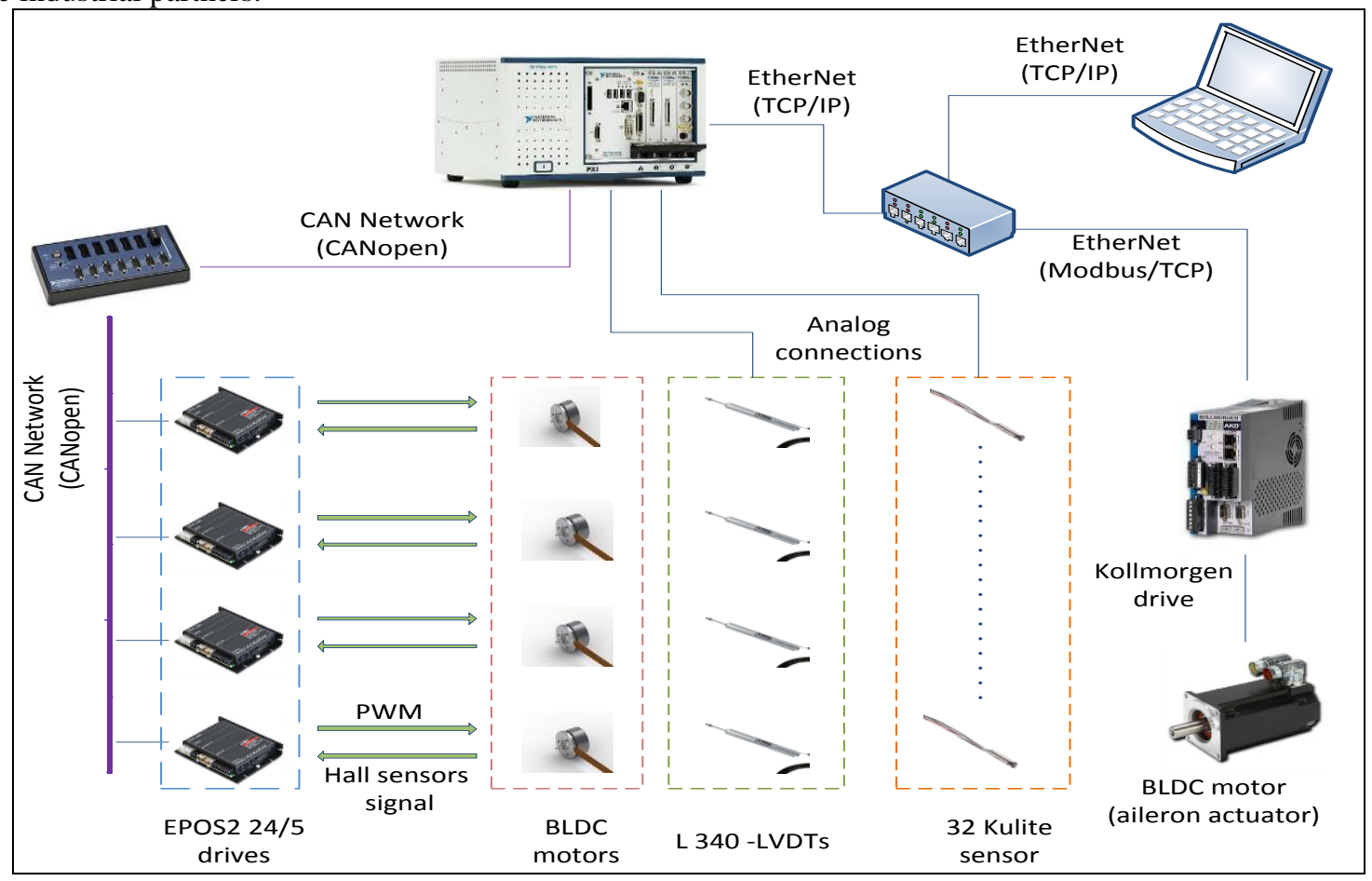

Figure 4 Overview of the morphing wing control system 


\subsection{Morphing Aileron}

An important component of the wing tip, with high impact on its aerodynamic performances, was the aileron. The conventional aileron, found on most aircraft wings, has a disadvantage that emboldened the research for a concept to replace it. The disadvantage of the conventional aileron lies in the manner in which it changes the camber of the wing. The aileron rotates around its hinge point, and thus creates a discontinuity of the slope of the airfoil camber line that should be considered over the upper and lower surfaces. For high deflection angles, this discontinuity can lead to premature boundary layer separation and a loss of efficiency for the aileron.

Therefore, the concept of a morphing aileron has been developed to replace the conventional rigid aileron, and thus to avoid the problem of the discontinuity. In their paper, R. Pecora $e t a l^{29}$ have demonstrated the potential of a kinematic rib-based morphing structural system for a shape changing trailing edge device of a medium range aircraft. I. Dimino $e t a l^{30}$ have studied the safety and reliability aspects associated with the use of morphing trailing edge device in a flying aircraft. Also, Barbarino and Pecora ${ }^{31}$ and Ameduri and Brindisi ${ }^{32}$, have shown the possibilities of using the SMA materials when developing shape changing devices by using an airfoil morphing model and a morphing flap device equipped with SMA actuators. G. Diodati $e t a l^{33}$ have analysed the performances towards fuel consumption reduction of an adaptive trailing edge for a medium-size aircraft.

Figures 5 and 6 present the morphing aileron that was developed by the Italian partners. By preserving the standard functionality as a conventional rigid aileron, morphing enabled an adaptive camber variation through a selfcontained kinematics driven by electromechanical actuators. The inner structure consisted of a segmented "fingerlike" architecture. Each rib was divided in three blocks connected by hinges and links, enabling relative rotation among the components according to a specific gear ratio. In such a manner, the aerodynamic shapes spanned from a target baseline to morphed configuration in the range of \pm 7 degrees through an un-shafted and distributed actuation ( G. Amendola et $\mathrm{al}^{34}$ ).

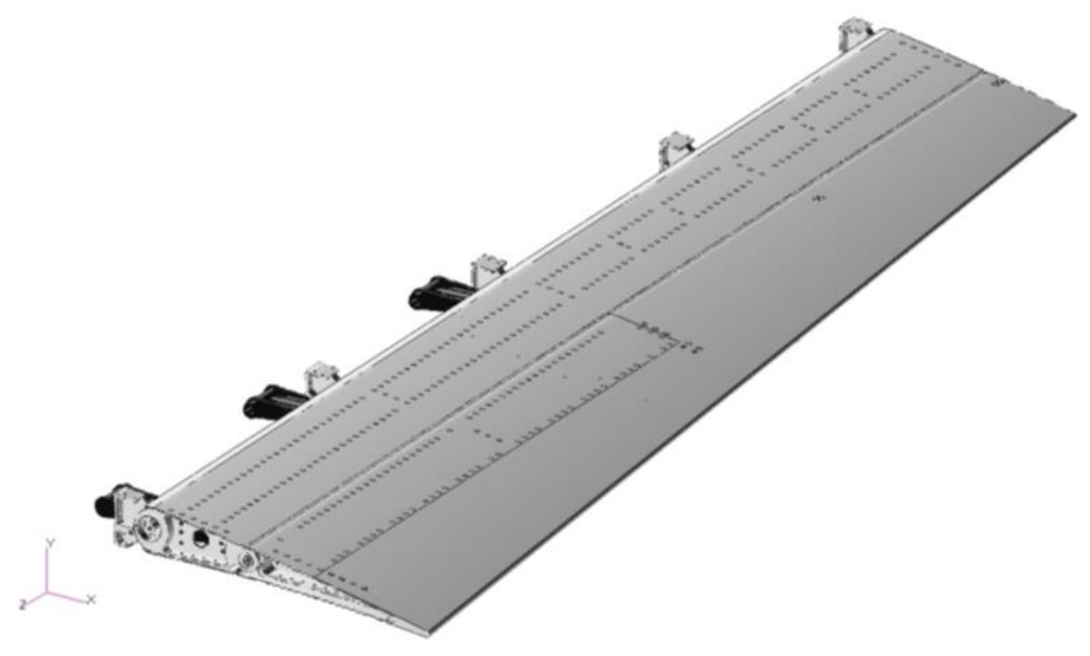

Figure 5 Morphing aileron system 


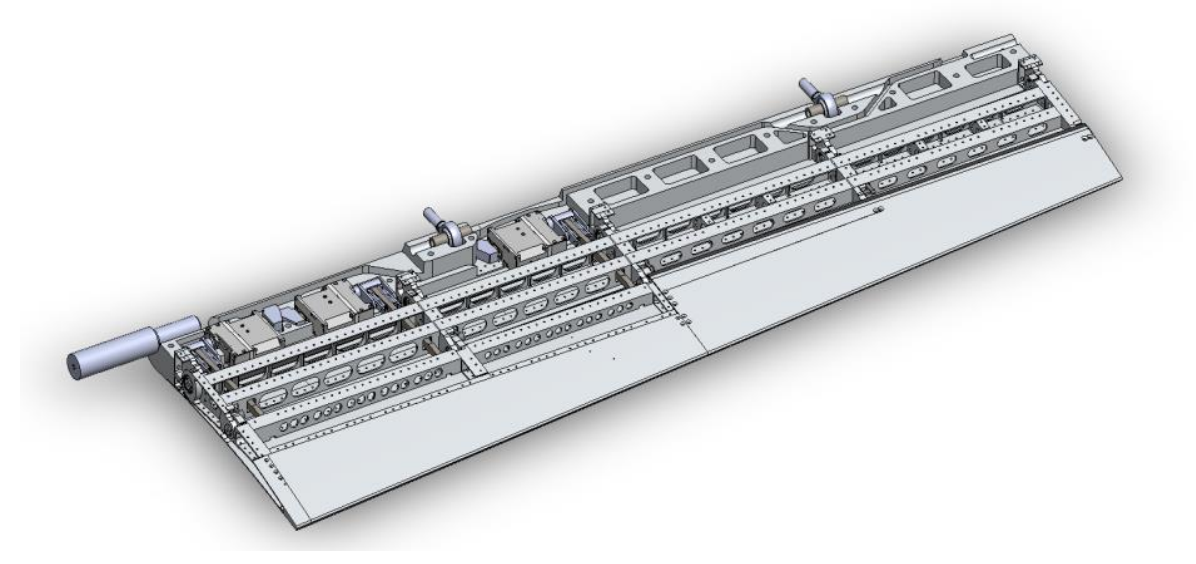

Figure 6 Morphing aileron internal structure

\section{Shape Optimization and Aerodynamic Analysis}

\subsection{Aerodynamic optimization with Genetic Algorithm and Xfoil solver}

During the wind tunnel tests, both the upper surface of the wing and the aileron shapes were actively morphed based on the numerical optimization results. The deformation of the upper surface of the wing was driven by four displacements points, resulted from the optimization process with Genetic Algorithm. Each set was calculated for a flight condition (combination of speed, Reynolds number, angle of attack and aileron deflection). Each set of four numerical displacements correspond to the set of four displacements of the electrical actuators installed in the wing box. For the aileron morphing, the optimization has provided a guiding shape for each desired deflection, while respecting constraints related to the constant thickness of the aileron, constant slope when aileron was morphing, and established convention for measuring the aileron deflection angle.

It was assumed that the central region of the wing, between the two center ribs on which the actuators were installed, would have a planar shape, thus the flow in this area would have bi-dimensional characteristics. Therefore, the optimization was conducted on the wing's airfoil.

All the optimization, for both morphing upper surface and morphing aileron was performed with an 'in-house' developed genetic algorithm optimizer. The genetic algorithm optimizer was coupled with a cubic spline routine for upper surface airfoil reconstruction, and with the XFoil aerodynamic solver for fast analysis of the optimization candidates. General schematics of the optimization software applied to the morphing wing problem are presented in Figure 7.

The genetic algorithm optimizer used a tournament process and a two-step cross-over function to speed up its convergence. The optimal mutation parameters, the probability and the amplitude of mutation, were defined based on percentages of the population and on the maximum displacements allowed. The optimizer was set to end the optimization after a total of 40 generations had passed. The fitness function, $F_{f}$, was based on multiple objective functions developed from the aerodynamic parameters that were calculated by XFoil. The aerodynamic parameters are: the lift and drag coefficients, pressure distribution, skin friction coefficient and upper surface transition location. 


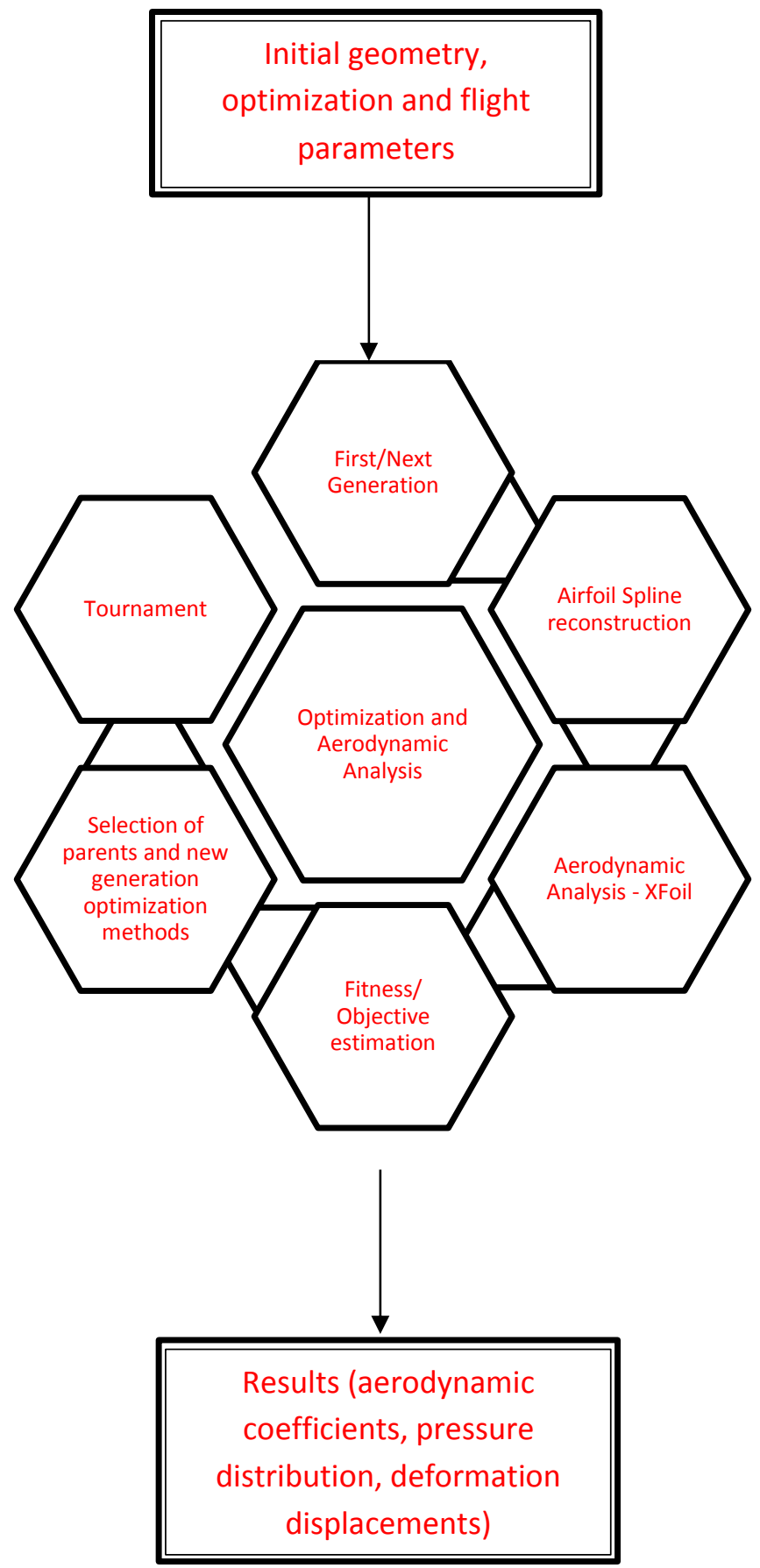

Figure 7 Genetic algorithm optimizer - general schematics

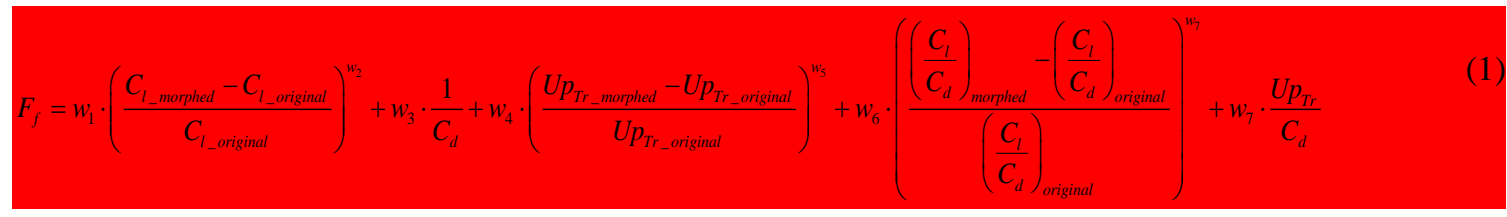


The results obtained by the optimization were the actuators' displacements for the upper surface skin and the morphed shapes for the morphing aileron.

The result obtained by the optimization algorithm were compared to the results obtained with two other optimizers, the artificial bee colony and the gradient methods, which were validated with experimental results from the CRIAQ MDO 505 wind tunnel test sessions and from other morphing wing projects ${ }^{35-36}$.

In Koreanschi $e t a l^{37}$, the genetic algorithm used for the optimization of the upper surface of the wing and for the aileron morphing was described in detail, with full parameters choices, fitness function, cross-over, mutation, convergence studies and comparisons with two other optimization methods - the ABC and the Gradient methods. The optimization model was found to be robust and reliable and its results were validated using experimental data.

\subsection{CFD aerodynamic analysis - Flow Equations, Turbulence and Transition Models}

CFD simulations were performed to simulate the flow past the wing under the wind tunnel test flow conditions and setup. The dynamics of fluid flow are governed by the Navier-Stokes equations, which are representative to the fundamental principles of mass, momentum and energy conservation.

The numerical computations were performed with the ANSYS FLUENT solver ${ }^{38}$. The steady-state flow equations were solved using a projection method, achieving the constraint of mass conservation by solving the pressure equation, with the pressure-velocity coupling accomplished by using a high-order Rhie-Chow scheme. The cell-face values of the pressure were interpolated using a second-order central differencing scheme, while for all other variables, including the turbulence and transition model equations, a second-order upwind scheme was used. The discrete nonlinear equations were solved in a fully implicit, coupled manner. Convergence acceleration was achieved with a coupled Algebraic Multi-Grid (AMG) approach, using a block-method Incomplete Lower-Upper (ILU) factorization scheme as the linear system smoother.

For turbulent flows, the Reynolds Averaging Navier Stokes (RANS) technique is used to decompose the instantaneous flow variables into their average values and turbulent fluctuations, while the Boussinesq eddyviscosity hypothesis is used to relate the Reynolds stress tensor and turbulent heat flux terms to the average flow variables.

The turbulent viscosity and the kinetic energy are determined using the $k-\omega$ Shear Stress Transport (SST) model $^{39}$. The SST model represents a combination of the $k-\omega$ model, used in the near wall region, and the $k-\varepsilon$ model, used for the rest of the flow. Thus, it achieves both accurate boundary layer representation up to the viscous sub-layer, and insensitivity to boundary conditions at free-stream flow.

In order to include the effects of laminar flow, and to model the laminar-to-turbulent transition process, the $\gamma-R e_{\theta t}$ model is used ${ }^{36}$.

The transition onset is controlled by an empirical correlation between $R e_{\theta c}$, the critical Reynolds number where the intermittency starts to increase in the boundary layer and $\overline{R e}_{\theta t}^{40}$. The model contains correction terms to account for laminar separation-induced transition and strong pressure-gradient flows. Coupling of the $\gamma-R e_{\theta t}$ transition model with the $k-\omega$ SST turbulence model is done by modifying $P_{k}$ and $D_{k}$, which are the turbulent kinetic energy production and the destruction terms, and thus deactivating the turbulence model for the laminar boundary layer region.

\subsection{Grid Convergence Study}

The structured meshes used for the numerical simulation were generated using the ICEM-CFD software. A grid convergence study was performed in order to evaluate the mesh density required to obtain grid-independent aerodynamic coefficients values. Four meshes of increasing cell density were generated, and each one was analysed at a Mach number of 0.15 , a Reynolds number of $4.53 \mathrm{E}+06$ (calculated with the wing mean aerodynamic chord) and an angle of attack of $0^{\circ}$. The details regarding the wall cell density for the generated meshes are presented in Table 1. 
Table 1 Details about the four generated meshes

\begin{tabular}{|c|c|c|c|}
\hline Mesh type & Chord-wise cells on wall & Span-wise cells on wall & Maximum y+ \\
\hline Coarse & 100 & 40 & 2.66 \\
\hline Medium & 200 & 80 & 1.33 \\
\hline Fine & 400 & 160 & 0.66 \\
\hline Extra Fine & 800 & 320 & 0.33 \\
\hline
\end{tabular}

The wing aerodynamic coefficients values (lift, drag and pitching moment coefficient about the root section quarter chord point) and the transition point locations on the upper surface, at $37 \%$ and $75 \%$ of the span stations are presented in Table 2. The transition point locations were determined using the intermittency variable $\gamma$ distribution calculated with the $\gamma-R e_{\theta t}$ model. The table shows that the difference in aerodynamic coefficient values between the Fine mesh level and the Richardson extrapolation of the convergence study is less than $1 \%$, therefore, the Fine mesh provides sufficiently accurate results. It can be observed that the $\gamma-R e_{\theta t}$ model requires having a good stream-wise mesh refinement level prior achieving the grid convergence or the transition point location (as the grid convergence of the drag coefficient maybe affected through the variation of the laminar flow region length).

Table 2 Results obtained for the grid convergence study

\begin{tabular}{|c|c|c|c|c|c|}
\hline Mesh type & CL & CD & Cm & $\begin{array}{c}\text { Transition at 37\% of } \\
\text { span (\% of local } \\
\text { chord) }\end{array}$ & $\begin{array}{c}\text { Transition at 75\% } \\
\text { of span (\% of local } \\
\text { chord) }\end{array}$ \\
\hline Coarse & $1.531 \mathrm{E}-01$ & $1.308 \mathrm{E}-02$ & $-9.235 \mathrm{E}-02$ & $13.4 \%$ & $3.4 \%$ \\
\hline Medium & $1.587 \mathrm{E}-01$ & $9.855 \mathrm{E}-03$ & $-9.264 \mathrm{E}-02$ & $48.2 \%$ & $32.8 \%$ \\
\hline Fine & $1.593 \mathrm{E}-01$ & $9.621 \mathrm{E}-03$ & $-9.273 \mathrm{E}-02$ & $57.5 \%$ & $36.9 \%$ \\
\hline Extra Fine & $1.596 \mathrm{E}-01$ & $9.609 \mathrm{E}-03$ & $-9.274 \mathrm{E}-02$ & $58.0 \%$ & $37.1 \%$ \\
\hline $\begin{array}{c}\text { Richardson } \\
\text { Extrapolation }\end{array}$ & $1.597 \mathrm{E}-01$ & $9.605 \mathrm{E}-03$ & $-9.276 \mathrm{E}-02$ & $58.2 \%$ & $37.1 \%$ \\
\hline
\end{tabular}

The characteristics of the meshes used to perform the simulations were determined based on the results of the grid convergence studies. In order to ensure that the same meshing parameters were used for all the morphed wing cases, an automatic mesh generation procedure was implemented by creating a script to be used for the ICEMCFD code. The automatic procedure can also handle rigid aileron deflections between $\pm 7^{\circ}$.

The meshes were constructed based on the Fine mesh level created for the convergence study, and include 400 cells around the wing section (200 cells on both the lower and upper surfaces), and 160 cells in the direction of the span ( 80 cells on both the lower and upper surfaces). The wall normal spacing was set to $3.0 \mathrm{E}-06 \mathrm{~m}$, refined enough to provide the required $y+<1$ condition. Figures 9 and 8 present two cross-section views of the mesh constructed around the un-morphed wing. The results provided for the un-morphed wing were also obtained for the morphed shapes of the wing. 


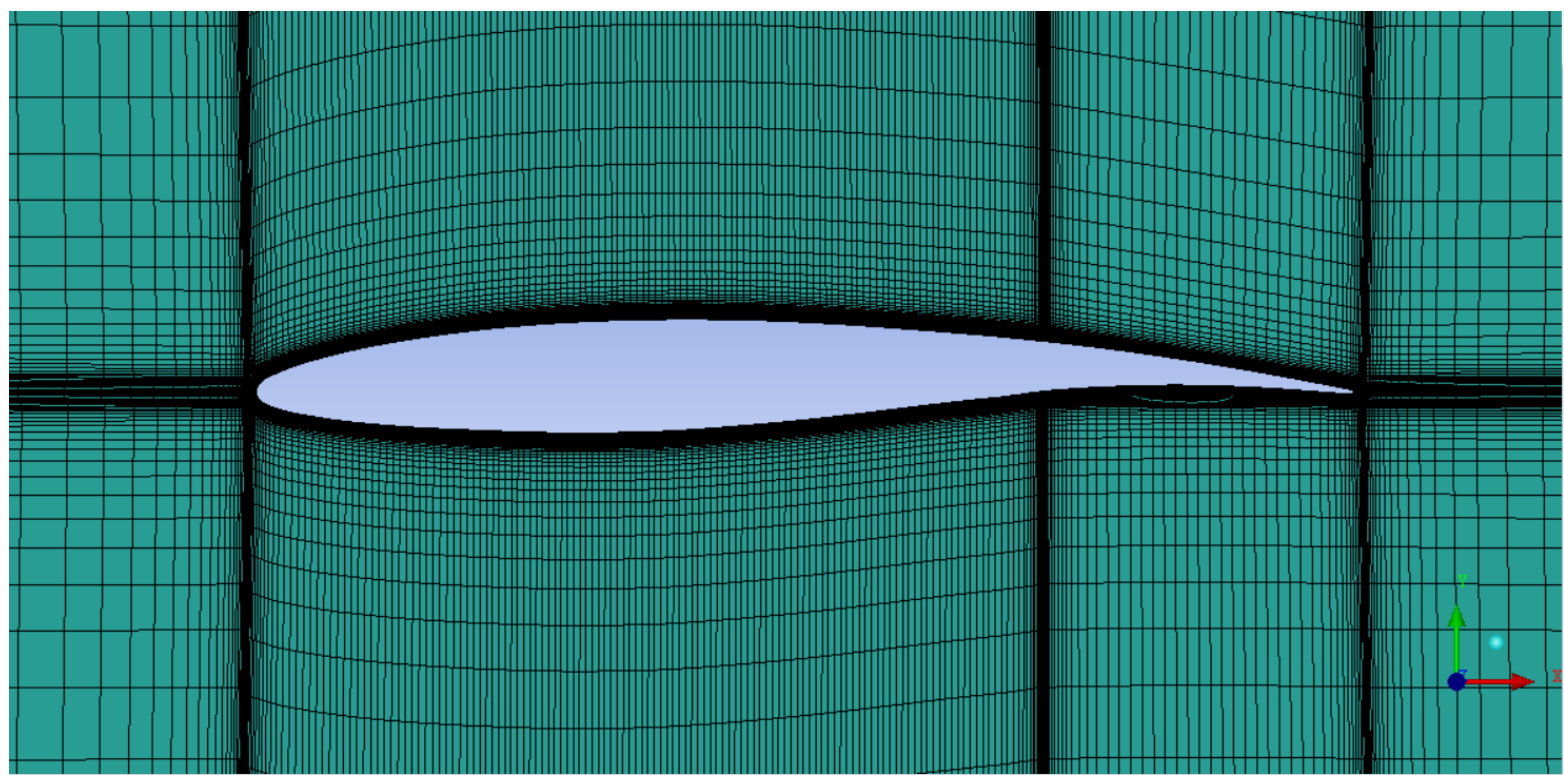

Figure 8 Chord-wise cross-section view of the mesh

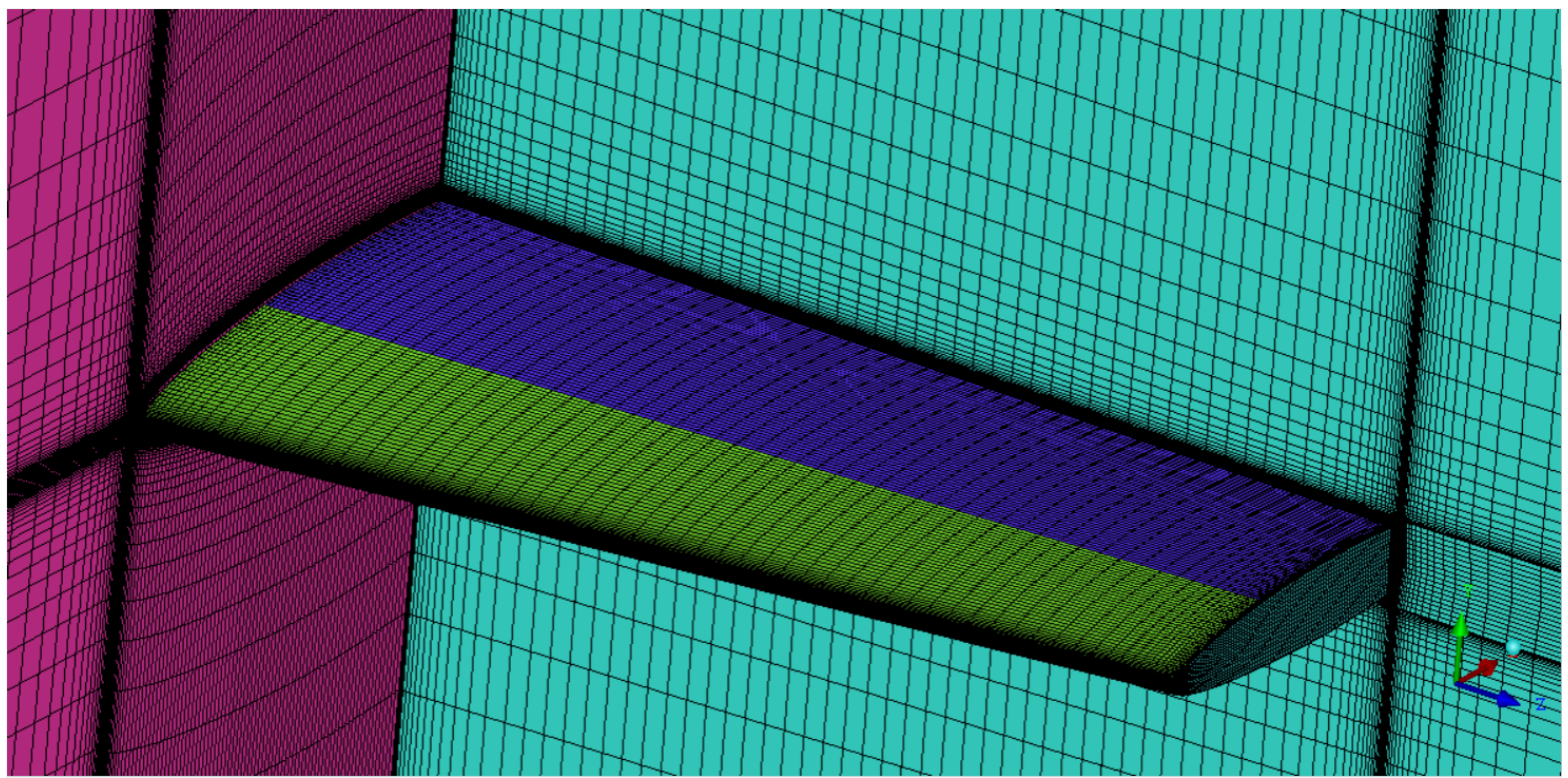

Figure 9 Spanwise cross-section view of the mesh

\section{Morphed Geometries}

\subsection{The Theoretical Optimized Upper Surface Shapes}

The core concept of an active morphing of the wing upper surface is to provide an optimized airfoil shape for each flight condition. A single point optimization must be performed for each combination of Mach number, Reynolds number and angle of attack. This procedure increases the aerodynamic performance of the shape-changing airfoil (with respect to the desired optimization objective) compared to the multi-point designed baseline airfoil.

Aerodynamic optimizations were performed to determine the actuator-driven displacements required to improve the performance of the morphing wing with respect to the original wing. In order to reduce the computational time, the aerodynamic optimizations were performed under two-dimensional flow assumption using the XFOIL solver ${ }^{41}$, and 
an in-house genetic algorithm optimizer, for local flow conditions (local Reynolds number and angle of attack) calculated for the mean aerodynamic chord of the wing model $^{42}$.

For the numerical optimizations, the wing upper skin shapes were approximated using cubic splines, as function of the actuators displacements. This mathematical model was chosen because it enforces the tangency condition with the rigid part of the wing airfoil (up to the curvature continuity given by the second derivative), it provides an iso-arc-length condition and it shares mathematical properties with a beam bending under an applied load. Due to constraints related to structural rigidity of the composite skin, the actuator displacements were limited to $\pm 3.5 \mathrm{~mm}$, while the maximum difference between the two displacements was limited to $6 \mathrm{~mm}$.

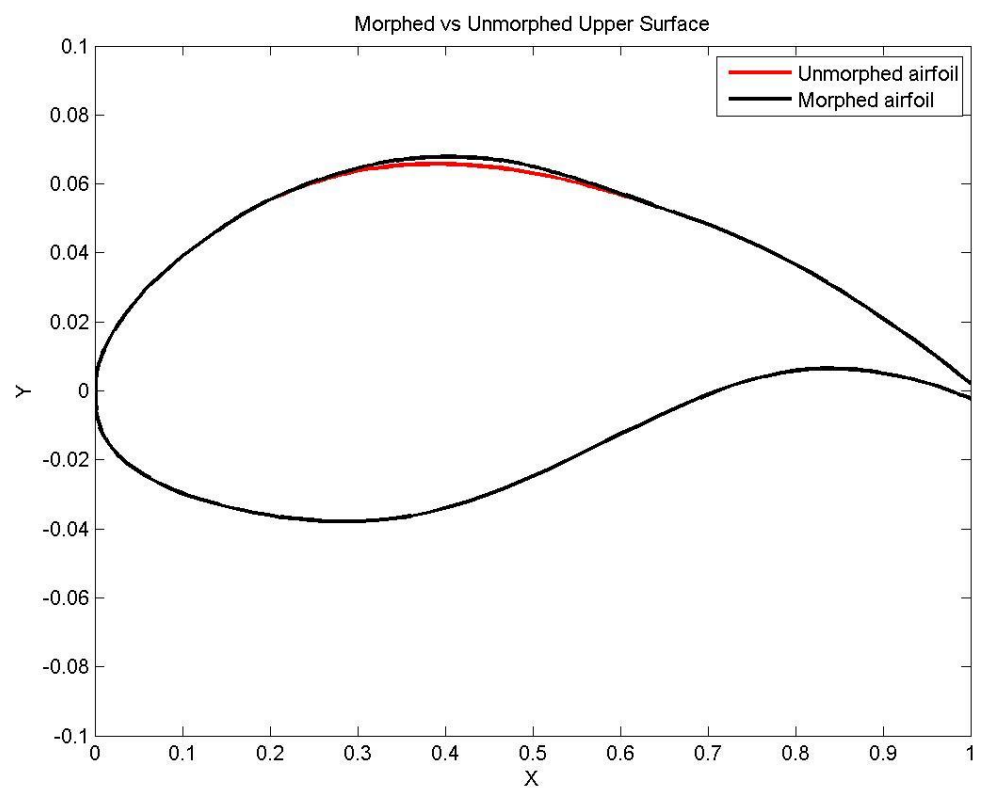

Figure 10 Unmorphed airfoil versus Morphed airfoil - upper surface comparison

\subsection{Aileron optimization}

The optimization of the aileron shape was performed using the same genetic algorithm optimizer that was developed for the upper surface morphing concept. The algorithm was applied to series of nodes along the camber line. Each node was displaced according to the constraints and the desired deflection and the displacement of each node engendered the movement of the next node until the whole aileron shape was deformed.

For the conventional aileron, the main problem resided in the rotation of the entire control surface around its hinge point, which creates a discontinuity of the slope of the airfoil camber line. The discontinuity is also reflected over the upper and lower surfaces of the wing and aileron articulation. At high deflection angles, the discontinuity can lead to premature boundary layer separation, and to a loss of efficiency of the control surface.

Consistence between the conventional and the morphed 'aileron deflection angles' was a constraint that was taken into account. The overall aileron deflection angle, calculated as the angle between the horizontal (which is defined as the position of the aileron at zero degree deflection) and the tip of the trailing edge of the morphed aileron shape, must remain consistent to the overall deflection angle of a conventional aileron.

Another constraint was related to the 'camber line' of the aileron. The curvature of the camber line must maintain a constant slope direction from the articulation point to the tip of the aileron.

The aileron camber line has been divided into several chord-wise sections; each defined by a starting and an ending point. The starting point of the first section coincided with the original hinge point, while the ending point of the last section coincided with the tip of the trailing edge. For each point along the camber line, two corresponding points on the upper and lower surfaces were defined based on the local thickness of the airfoil section. In addition, for each section, the coordinates of the hinge point were calculated, so that the rotation of any section with respect to the previous section preserved the continuity of the camber line.

Using this method, the deflection of any chord-wise section, with respect to the section directly upstream of it, preserves both the local thickness of the airfoil and the length of the segment, since rotation does not modify any other geometrical characteristics. If all segments were rotated in the same direction, the overall deflection of the 
aileron, as measured at the trailing edge and using the original hinge point as reference, was simply the sum of all segments rotations, where each segment was rotated with reference to the segment immediately upstream of it.

By controlling the number of chord-wise segments, as well as the local rotation angles for each individual segment, a great flexibility in the shape changing of the aileron could be obtained, see Figure 11. All these degrees of freedom could be adjusted to match the technological limitations associated to the fabrication process of such an aileron.

In Koreanschi et $a t^{43}$, details on the morphing techniques used, as well as numerical comparisons are provided for various flight cases where the wing uses the conventional and the morphing aileron in turn in combination with the upper surface morphing skin. The results have shown improvements in the lift coefficient of up to $19 \%$, using either of the techniques presented in the paper for aileron shape determination, and it has shown the possibility of influencing the behavior of the boundary layer and perhaps to delay its detachment.

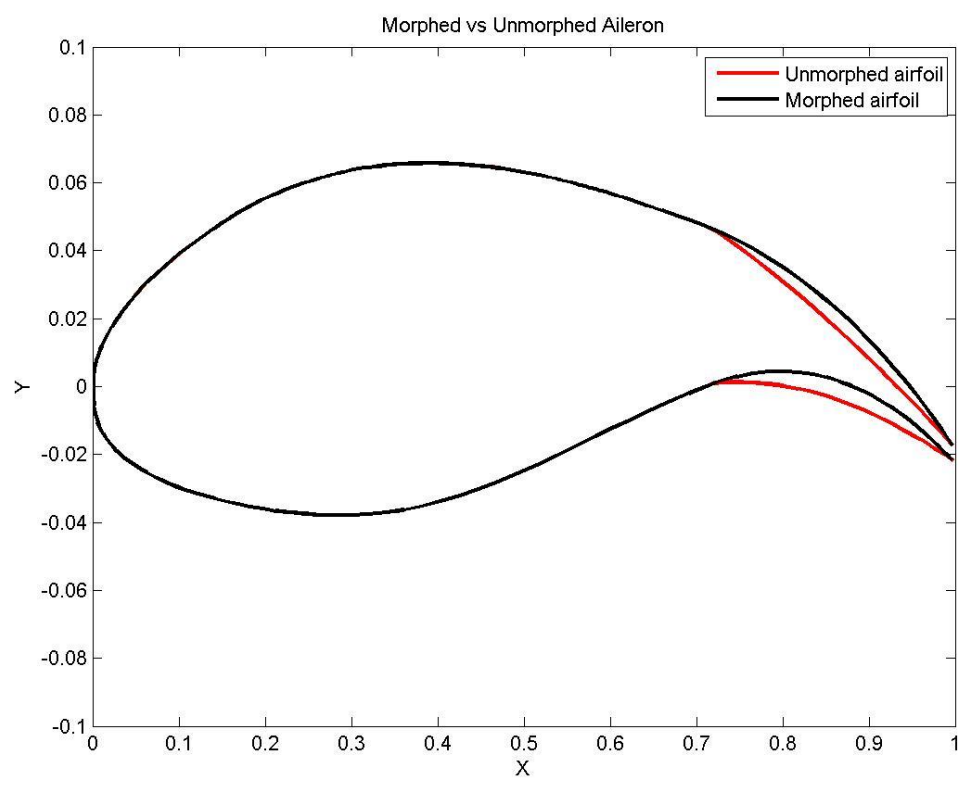

Figure 11 Unmorphed airfoil versus Morphed airfoil - Aileron shape comparison.

\section{Wind Tunnel Testing}

\subsection{Wind Tunnel Description}

The wind tunnel tests were performed at the National Research Council Canada at the $2 \mathrm{~m} \times 3 \mathrm{~m}$ atmospheric closed circuit subsonic wind tunnel. The atmospheric wind tunnel can operate at a maximum Mach number of 0.33 .

Figure 12 presents the MDO 505 CRIAQ project morphing wing-tip model installed in the tunnel test section, viewed from both the leading edge (Figure 12a) and the trailing edge (Figure 12b) of the wing. 


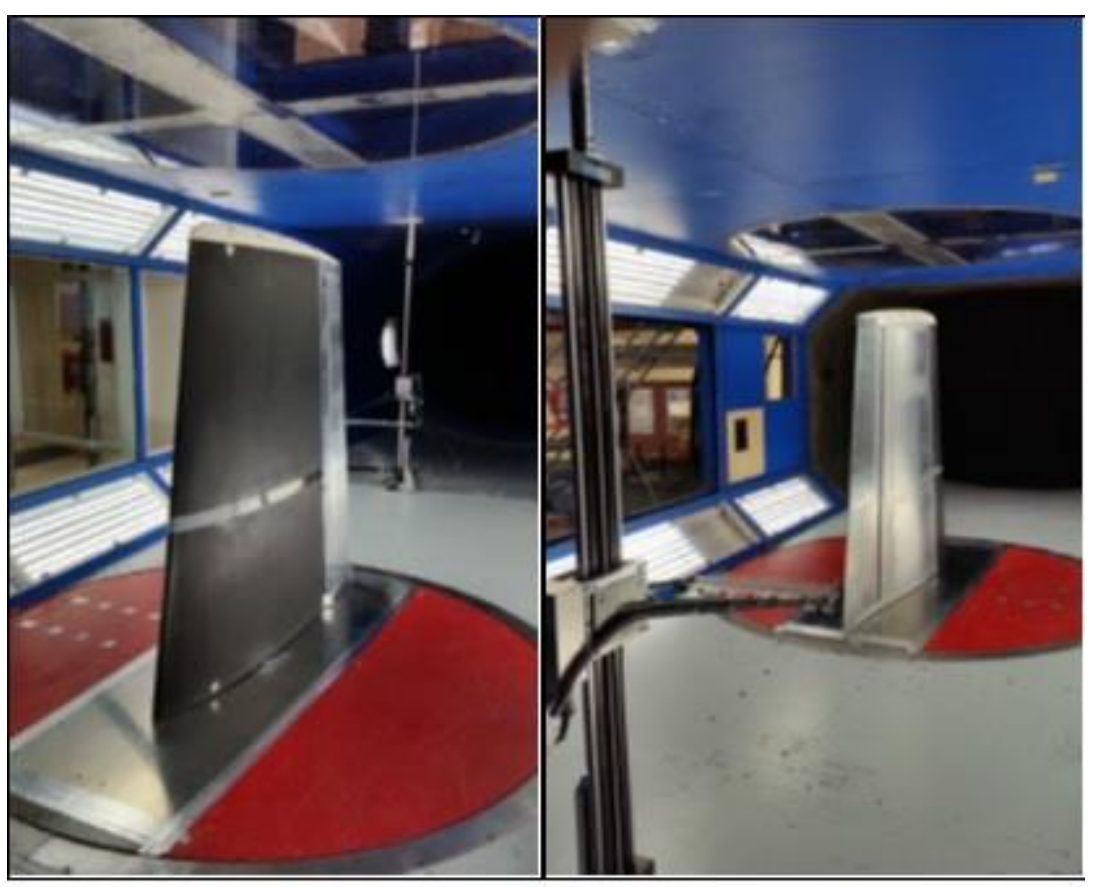

a)

b)

Figure 12 CRIAQ MDO 505 Project wing model setup in the wind tunnel test section;

\subsection{Data Measurement Tools}

The upper surface flexible skin of the wing demonstrator was equipped with 32 high precision Kulite piezoelectric-type transducers, for pressure measurement on the flexible skin. The measured pressures were processed in real time to determine the laminar-to-turbulent transition location. The sensors were installed in two chordwise staggered lines (with 16 Kulite sensors on each line), respectively at spanwise positions of $0.600 \mathrm{~m}$ and $0.625 \mathrm{~m}$ from the wing root section. In addition to the Kulite piezoelectric sensors, 60 static pressure taps were installed (30 taps on each line), on the wing leading edge, lower surface and aileron, thus providing complete experimental pressure distribution around the wing cross section at $40 \%$ of the wing span. The pressure sensors were installed in a staggered fashion to minimize any interference in between.

Infra-red (IR) thermography camera visualizations were performed for capturing the transition region over the entire wing model surface. The wing leading edge, its upper surface flexible skin and the aileron interface were coated with high emissivity black paint to improve the quality of the IR photographs. The span-wise stations, where the two pressure sensors lines were installed, were not painted, in order to not influence the pressure reading quality 44.

The IR thermography visualization allowed the identification of the transition region between laminar and turbulent regimes, based on the analysis of the model surface temperature. The turbulent flow regime increases the convective heat transfer between the model and the flow with respect to the laminar boundary layer. As a result, a flow temperature change, introduced by the wind tunnel heat exchanger system, will cause different temperature changes over the model, depending on the behavior of the boundary layer (laminar, transitional and turbulent states). Figure 13 presents an example of the IR visualisation of the wing model upper surface transition, for one flight condition (Mach number of 0.15, angle of attack of $1^{\circ}$ and no aileron deflection) and for both un-morphed (left figure) and morphed (right figure) skin shapes. 

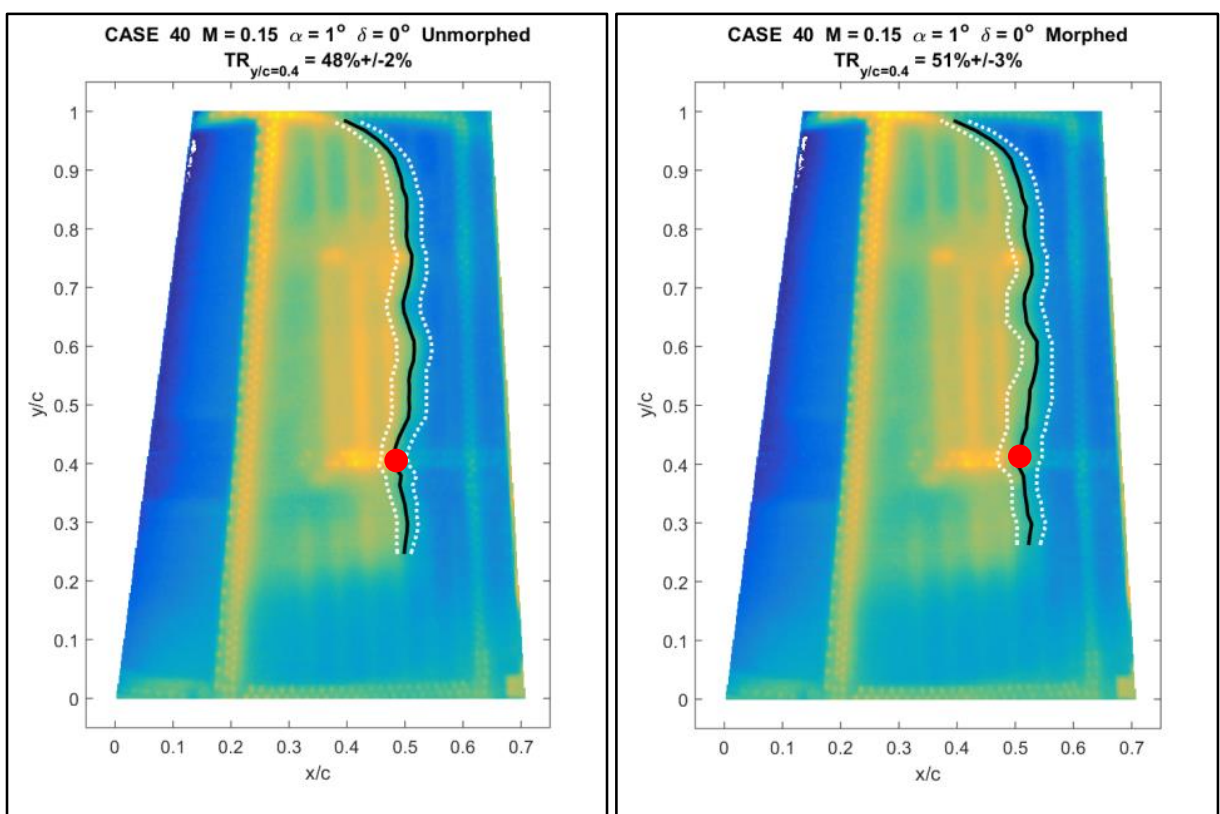

Figure 13 IR visualisation of the laminar-to-turbulent transition region on the upper surface for both un-morphed (left) and morphed (right) skin shapes

The black line represents the average transition line on the wing upper surface, and its variation as function of the span-wise position can clearly be observed. The two dashed white lines represent the estimated extent of the transition region, determined as function of the chord-wise temperature gradient existing between laminar and turbulent regimes. The transition from laminar to turbulent flow occurs over a narrow region and it was automatically detected for the wing upper surface using a MATLAB code that was specifically developed for the IR images post-processing ${ }^{45}$. The red dot corresponds to the estimated transition in the span-wise section situated at $0.612 \mathrm{~m}$ from the root section ( $40 \%$ of the model span), that is half-way between the two Kulite piezoelectric pressure sensors lines. The accuracy of the transition detection for this section was estimated to $\pm 2 \%$ of the local chord, based on the known Kulite positions and their thermal signatures in the images.

The experimental measurements also included the use of a wake rake pressure acquisition system, to measure the wing profile drag at different span-wise positions, and to use a wind tunnel balance that had the aim to measure the aerodynamic forces and moments.

To avoid the possibility of damaging the wing tip model during wind tunnel testing, and to be able to observe the wing vibration behaviour, three accelerometers were installed. The three accelerometers were installed in the wing box, aileron and wind tunnel balance respectively as shown in Figure 14. 


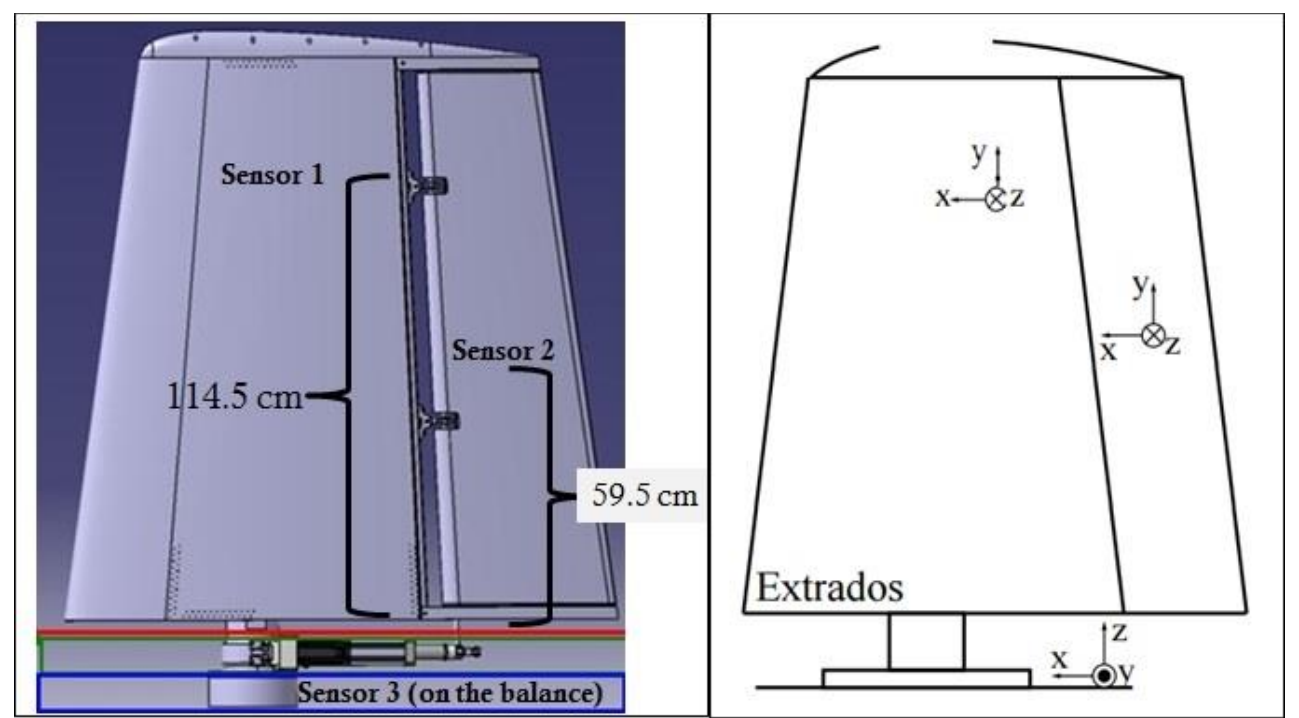

Figure 14 Positions and orientations of the accelerometers on the wing

At the end of the second wind tunnel set of tests the upper surface of the wing was measured using high-precision photogrammetry and the results were compared to the expected numerical values. It was expected that the morphed composite skin would reproduce the numerical shape within $0.25 \mathrm{~mm}$ of the desired shape along the actuator lines and under $1 \mathrm{~mm}$ at the center of the skin.

Figure 15 shows the scan results for the composite upper surface of the wing (aileron is not included in scan). $\triangle Z$ (mm). CASE: 82. CTRL: 2

RED: Kulite station. GREEN: Flexible skin outline.

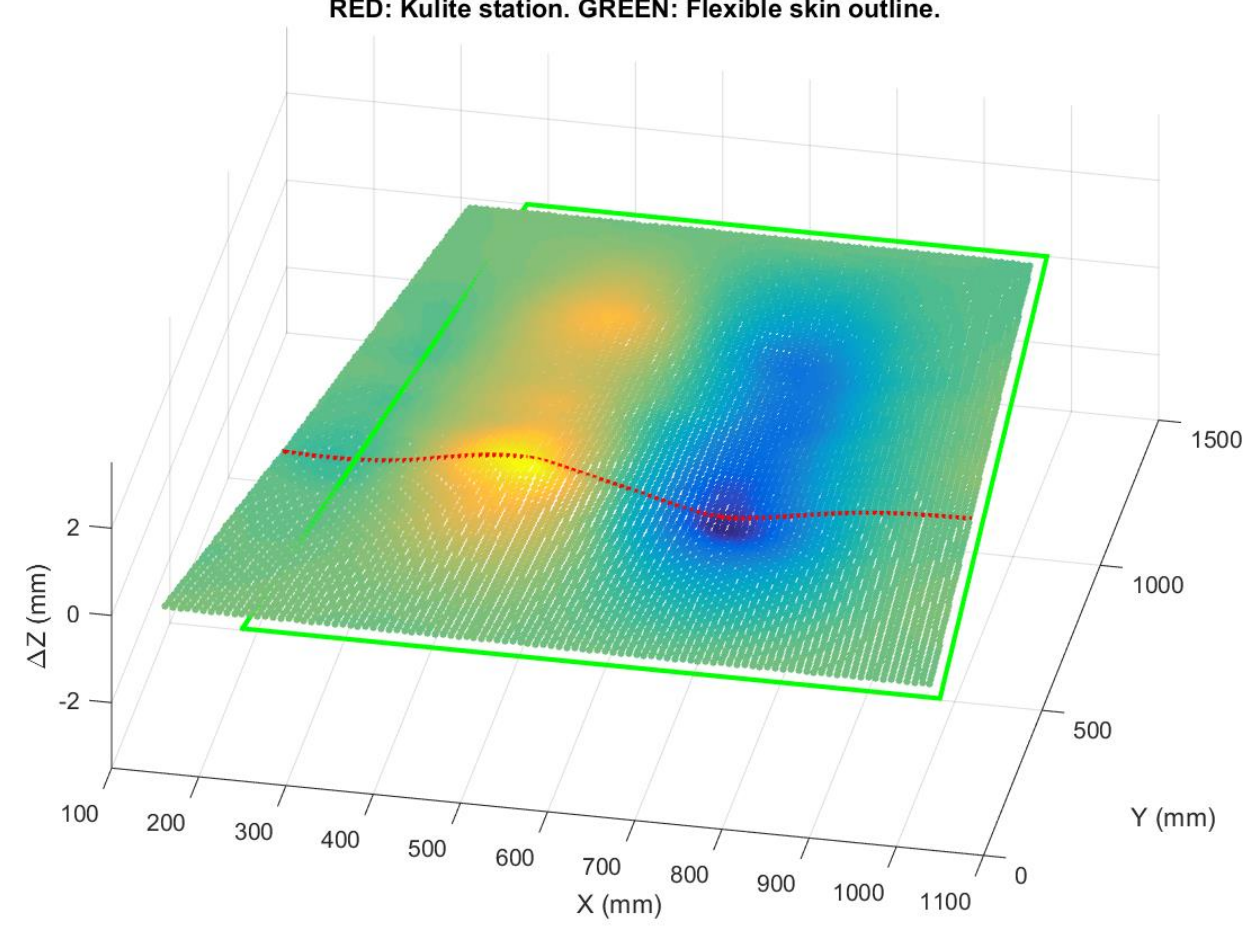

Figure 15 Photogrammetry of the composite upper surface for case $82\left(\mathrm{M}=0.2\right.$, angle of attack $=5^{\circ}$, aileron deflection $=-4^{\circ}$ )

The deformations presented in Figure 15 correspond to the actuator displacements presented in Table $3 \mathrm{a}$ below. 
Figures $16 \mathrm{a}, \mathrm{b}$ and c present the comparison between target and the actual deformation for case 58 and $550 \mathrm{~mm}, 950$ $\mathrm{mm}$ and $1150 \mathrm{~mm}$ span position. As it can be seen, the target and the real shape overlap, and the deformation was considered successful.

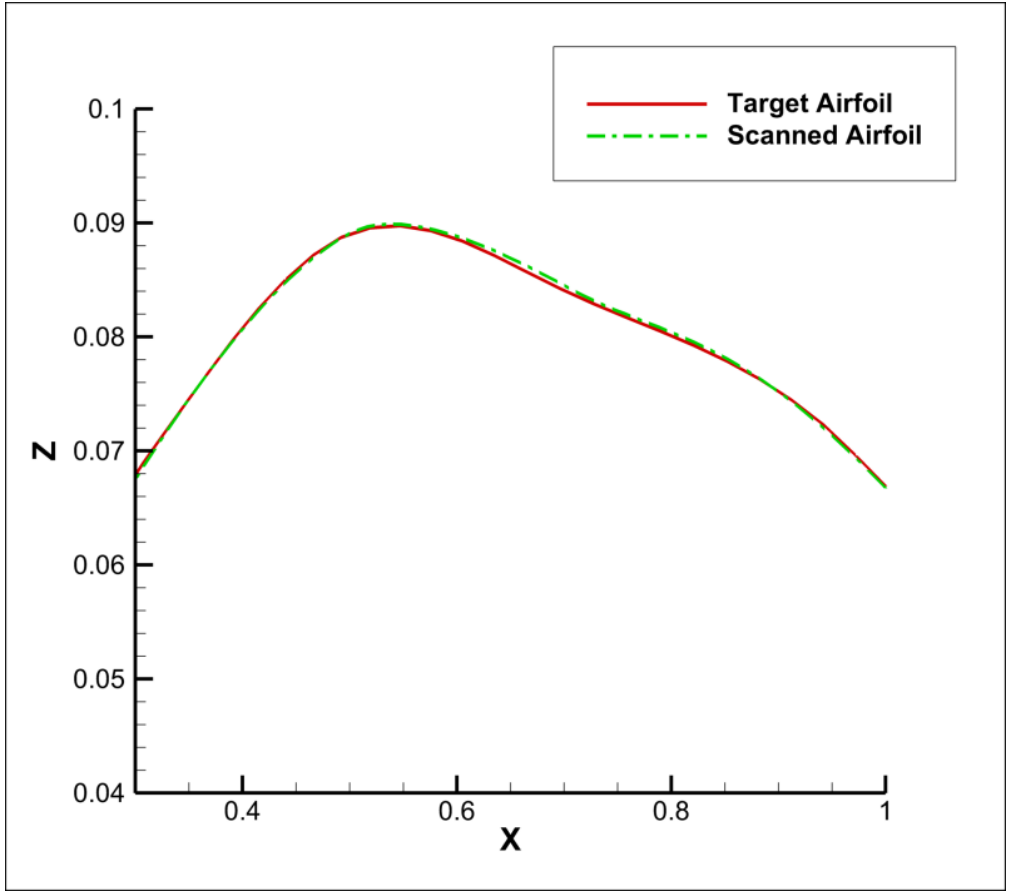

Figure 16a Target versus real wing upper surface deformation for case 58 at $550 \mathrm{~mm}$ span position

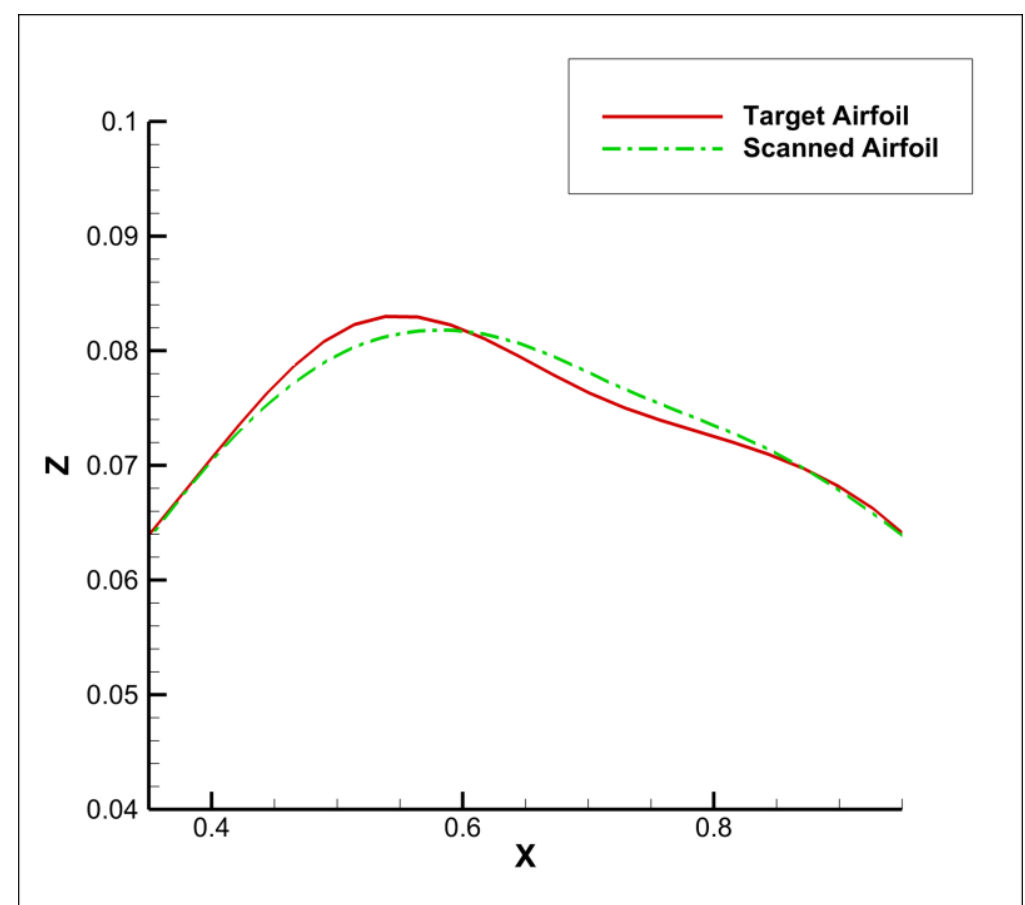

Figure 16b Target versus real wing upper surface deformation for case 58 at $950 \mathrm{~mm}$ span position 


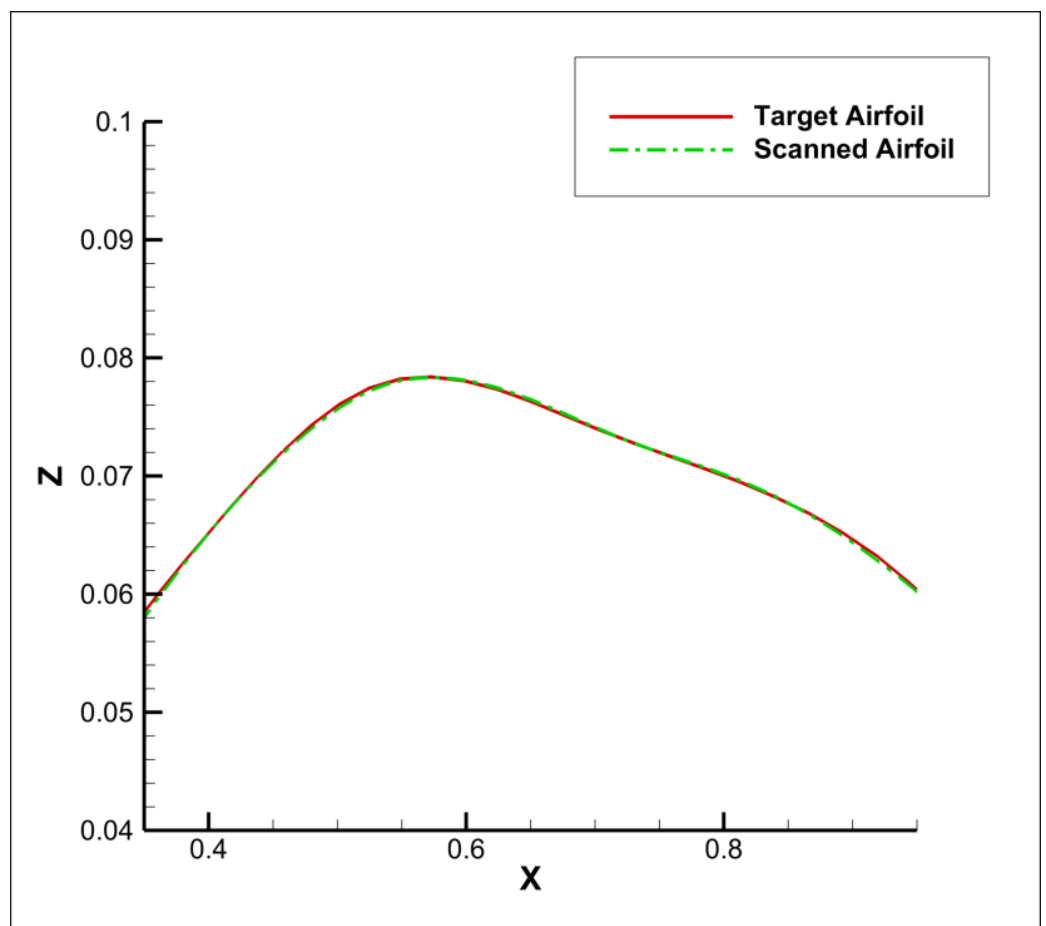

Figure 16c Target versus real wing upper surface deformation for case 58 at $1150 \mathrm{~mm}$ span position

The analysis of the measurement data has shown that the composite skin along the actuator lines has reproduced the desired shape within $0.3 \mathrm{~mm}$, while at the center it has less than $1 \mathrm{~mm}$ variation from the desired shape. Overall, the real morphing composite skin managed to reproduce the numerical shape within the expected limits due to the precision of the controllers used and to the specific design of the composite skin.

\section{Results and Discussion}

The wing demonstrator was tested during three sets of wind tunnel tests. During the first and second sets of wind tunnel tests, the wing was equipped with the conventional rigid aileron. During the third set of tests, the wing was equipped with the morphing aileron that was tested in conjunction with the morphing upper surface skin. The results presented in the first part of this section were obtained during the second set of wind tunnel tests, when the wing demonstrator was equipped with the morphing upper surface and the conventional aileron. The results presented in the second part of this section, were obtained during the third set of wind tunnel tests, when the wing demonstrator was equipped with the morphing upper surface and the morphing aileron. The first set of wind tunnel tests, consisted of 32 cases tested for the actuators' and aileron controllers, as well as for Infrared Imaging calibration.

\subsection{Results for the second set of wind tunnel tests - Wing equipped with morphing upper surface skin and conventional aileron}

The two-dimensional aerodynamic optimizations that determined the electrical actuators displacements were performed with the objective of controlling the extent of laminar flow on the upper surface of the wing model.

These optimizations were performed for several flight conditions (expressed in terms of Mach number, Reynolds number and angle of attack), and several rigid aileron deflection angles. A total of 97 flight cases were tested for the wing equipped with morphing upper surface skin and conventional aileron. The optimization and testing was carried for a range of angles of attack between -5 and 5 degrees, aileron deflections between -7 and 7 and speed range between Mach 0.15 and Mach 0.25. Due to the large number of tests carried, only twenty-two of the cases that were optimized, analysed and experimentally tested for laminar flow increase are presented in Table 3. The Reynolds 
numbers that correspond to the two Mach numbers are $4.28 \times 10^{6}$ and $5.27 \times 10^{6}$. A downwards aileron deflection was considered as positive, while an upwards aileron deflection was considered as negative.

Table 3 Test cases for which the wing tip airfoil was optimized for laminar flow improvement

\begin{tabular}{|c|c|c|c|c|c|c|c|c|c|c|c|c|}
\hline \multirow{2}{*}{ Mach } & \multirow{2}{*}{$\begin{array}{c}\text { Delta } \\
\text { aileron } \\
{\left[{ }^{\circ}\right]}\end{array}$} & \multicolumn{11}{|c|}{ Angle of Attack $\left[{ }^{0}\right]$} \\
\hline & & 0 & 0.5 & 0.75 & 1 & 1.25 & 1.5 & 2 & 2.5 & 3 & 4 & 5 \\
\hline 0.15 & 0 & - & - & C39 & $\mathrm{C} 40$ & $\mathrm{C} 41$ & $\mathrm{C} 42$ & $\mathrm{C} 43$ & $\mathrm{C} 44$ & $\mathrm{C} 45$ & - & - \\
\hline 0.2 & 4 & $\mathrm{C} 68$ & C69 & - & $\mathrm{C} 70$ & - & $\mathrm{C} 71$ & $\mathrm{C} 72$ & C73 & - & - & - \\
\hline 0.2 & -4 & C74 & C75 & - & C76 & - & $\mathrm{C} 77$ & $\mathrm{C} 78$ & C79 & $\mathrm{C} 80$ & $\mathrm{C} 81$ & $\mathrm{C} 82$ \\
\hline
\end{tabular}

Table 3a Actuators' displacements for the wind tunnel cases presented in Table 3

\begin{tabular}{|c|c|c|c|c|}
\hline Case & Actuator $1(\mathbf{m})$ & Actuator $2(\mathbf{m})$ & Actuator $3(\mathbf{m})$ & Actuator $4(\mathbf{m})$ \\
\hline 39 & $-1.33 \mathrm{E}-03$ & $1.52 \mathrm{E}-03$ & $-1.18 \mathrm{E}-03$ & $1.35 \mathrm{E}-03$ \\
\hline 40 & $-1.56 \mathrm{E}-04$ & $2.97 \mathrm{E}-03$ & $-1.38 \mathrm{E}-04$ & $2.64 \mathrm{E}-03$ \\
\hline 41 & $-3.67 \mathrm{E}-04$ & $3.00 \mathrm{E}-03$ & $-3.26 \mathrm{E}-04$ & $2.66 \mathrm{E}-03$ \\
\hline 42 & $-5.78 \mathrm{E}-04$ & $2.78 \mathrm{E}-03$ & $-5.13 \mathrm{E}-04$ & $2.46 \mathrm{E}-03$ \\
\hline 43 & $1.60 \mathrm{E}-03$ & $2.77 \mathrm{E}-03$ & $1.42 \mathrm{E}-03$ & $2.46 \mathrm{E}-03$ \\
\hline 44 & $2.23 \mathrm{E}-03$ & $2.08 \mathrm{E}-03$ & $1.98 \mathrm{E}-03$ & $1.85 \mathrm{E}-03$ \\
\hline 45 & $2.25 \mathrm{E}-03$ & $-9.09 \mathrm{E}-06$ & $2.00 \mathrm{E}-03$ & $-8.07 \mathrm{E}-06$ \\
\hline 68 & $-3.97 \mathrm{E}-04$ & $2.17 \mathrm{E}-03$ & $-3.52 \mathrm{E}-04$ & $1.92 \mathrm{E}-03$ \\
\hline 69 & $6.56 \mathrm{E}-05$ & $2.66 \mathrm{E}-03$ & $5.82 \mathrm{E}-05$ & $2.37 \mathrm{E}-03$ \\
\hline 70 & $1.66 \mathrm{E}-03$ & $3.21 \mathrm{E}-03$ & $1.47 \mathrm{E}-03$ & $2.85 \mathrm{E}-03$ \\
\hline 71 & $1.90 \mathrm{E}-03$ & $2.09 \mathrm{E}-03$ & $1.68 \mathrm{E}-03$ & $1.85 \mathrm{E}-03$ \\
\hline 72 & $2.26 \mathrm{E}-03$ & $3.21 \mathrm{E}-03$ & $2.00 \mathrm{E}-03$ & $2.85 \mathrm{E}-03$ \\
\hline 73 & $-1.25 \mathrm{E}-03$ & $-1.70 \mathrm{E}-03$ & $-1.11 \mathrm{E}-03$ & $-1.51 \mathrm{E}-03$ \\
\hline 74 & $-9.35 \mathrm{E}-04$ & $2.50 \mathrm{E}-03$ & $-8.30 \mathrm{E}-04$ & $2.22 \mathrm{E}-03$ \\
\hline 75 & $-1.22 \mathrm{E}-03$ & $2.01 \mathrm{E}-03$ & $-1.09 \mathrm{E}-03$ & $1.78 \mathrm{E}-03$ \\
\hline 76 & $-6.13 \mathrm{E}-04$ & $2.65 \mathrm{E}-03$ & $-5.44 \mathrm{E}-04$ & $2.36 \mathrm{E}-03$ \\
\hline 77 & $-4.55 \mathrm{E}-04$ & $3.42 \mathrm{E}-03$ & $-4.04 \mathrm{E}-04$ & $3.04 \mathrm{E}-03$ \\
\hline 78 & $-1.08 \mathrm{E}-05$ & $2.54 \mathrm{E}-03$ & $-9.55 \mathrm{E}-06$ & $2.25 \mathrm{E}-03$ \\
\hline 79 & $2.47 \mathrm{E}-04$ & $2.65 \mathrm{E}-03$ & $2.19 \mathrm{E}-04$ & $2.36 \mathrm{E}-03$ \\
\hline 80 & $2.28 \mathrm{E}-03$ & $2.62 \mathrm{E}-03$ & $2.03 \mathrm{E}-03$ & $2.33 \mathrm{E}-03$ \\
\hline 81 & $-2.73 \mathrm{E}-03$ & $-9.51 \mathrm{E}-04$ & $-2.42 \mathrm{E}-03$ & $-8.44 \mathrm{E}-04$ \\
\hline 82 & $2.75 \mathrm{E}-04$ & $-4.05 \mathrm{E}-04$ & $2.44 \mathrm{E}-04$ & $-3.60 \mathrm{E}-04$ \\
\hline
\end{tabular}

Where, Actuators 1 and 2 are located on the first actuation line at approximately $55 \mathrm{~cm}$ from the wing root, and Actuators 3 and 4 correspond to the second actuation line situated at $105 \mathrm{~cm}$ from wing root. The order of the actuators on each line is from leading edge, $32 \%$ of chord, towards trailing edge, $48 \%$ of chord.

For each case, the transition point location on the pressure sensors line was determined from the numerical simulation, and was further compared to the experimentally measured transition location, determined using the IR thermography. The transition point location was determined numerically by plotting the turbulence intermittency $\gamma$ versus the local chord, for the upper and lower wing surfaces. In order to consistently extract the transition location, the first derivative of the intermittency plot was used. Since the intermittency is approximately constant for the laminar boundary layer and its value significantly increases across the transition region, the first derivative can be 
used to identify this region of high gradient. The transition point was considered to be the most upstream point where the derivative becomes non-zero. As an example, Figure 17 shows the intermittency distribution at $0.612 \mathrm{~m}$ span-wise section, for case C39 original or un-morphed. The laminar-to-turbulent transition corresponds to the region of high gradient.

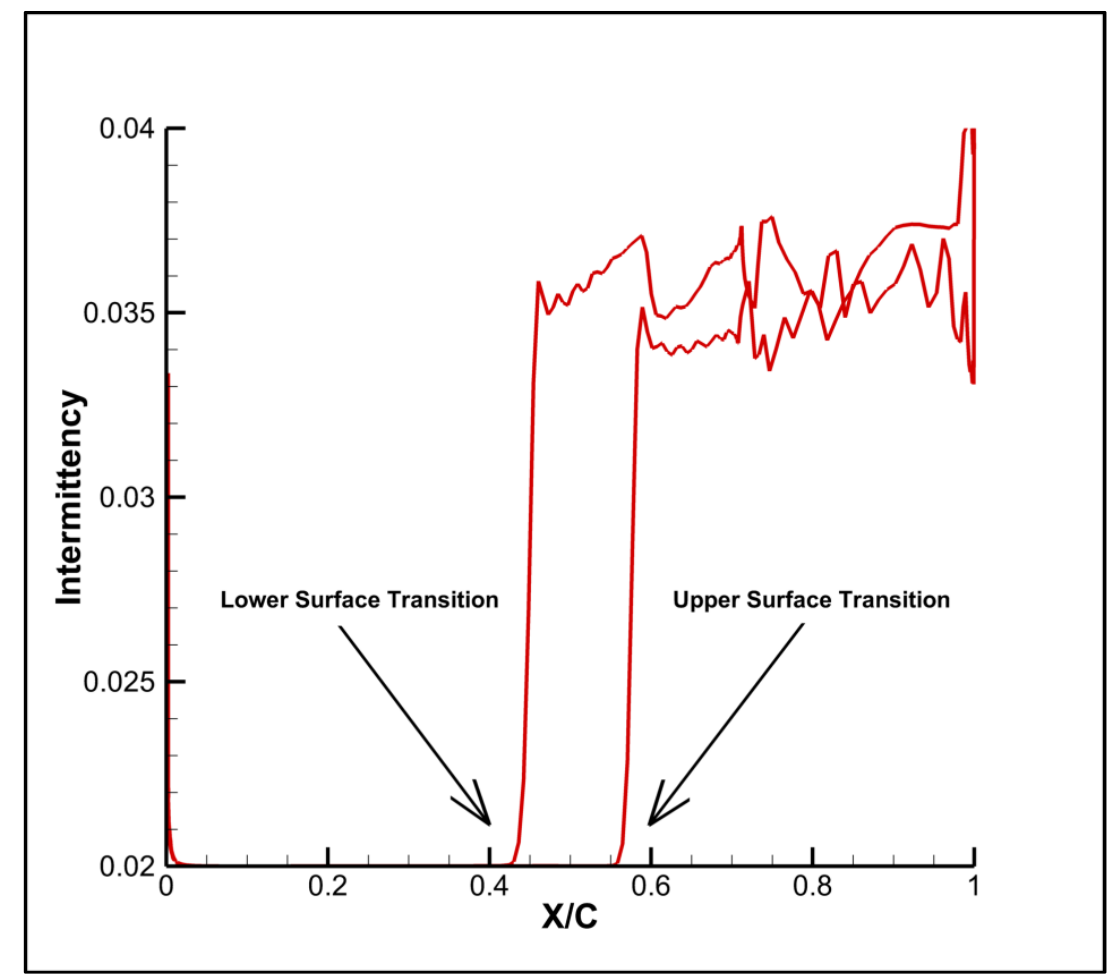

Figure 17 Transition detection for Case 39 un-morphed using the turbulence intermittency distribution

\subsubsection{Upper surface transition location}

In order to evaluate the optimization success of the wing tip demonstrator equipped with morphing upper surface, the experimental transition region of the morphed wing tip demonstrator was compared to the experimental transition of the original (un-morphed) wing tip demonstrator. The experimental transition region was provided by the Infra-Red Thermography data that was recorded during each of the flight case wind tunnel testing.

As such, two parameters were calculated: $\boldsymbol{\tau}$, which represented the difference between the morphed and unmorphed (original) transition region (TR) upper boundary values and described with how much the onset of the fully turbulent flow was modified,

$$
\begin{aligned}
& \tau=\text { Morphed }_{U B}-\text { UnmorphedTR }_{U B} \\
& U B=\text { upper }- \text { boundary }
\end{aligned}
$$

and $\lambda$, which represented the difference between the morphed and un-morphed (original) transition region (TR) lower boundary values and described with how much the boundary of the fully laminar flow was modified.

$$
\begin{aligned}
& \lambda=\text { Morphed }_{L B}-\text { Unmorphed }_{L B} \\
& L B=\text { lower }- \text { boundary }
\end{aligned}
$$


Table 4 presents the values of extension of the laminar region ( $\lambda)$, contraction of the turbulent region ( $\tau$ ), and the average transition extension of the un-morphed (original) and morphed transition region for the seven cases from Table 3.

Table 4 Presentation of $(\boldsymbol{\tau})$ and $(\lambda)$ parameters for each of the flight cases from Table 3

\begin{tabular}{|c|c|c|c|}
\hline Case No & $\begin{array}{l}\text { Extension of the Laminar } \\
\text { region (\% of chord) }(\lambda)\end{array}$ & $\begin{array}{c}\text { Transition Region average } \\
\text { (\% of chord) }\end{array}$ & $\begin{array}{l}\text { Contraction of the turbulent } \\
\text { region (\% of chord) }(\tau)\end{array}$ \\
\hline 39 & $-0.09 \%$ & $-0.09 \%$ & $-0.09 \%$ \\
\hline 40 & $3.76 \%$ & $1.76 \%$ & $2.76 \%$ \\
\hline 41 & $3.79 \%$ & $1.79 \%$ & $2.79 \%$ \\
\hline 42 & $2.19 \%$ & $2.19 \%$ & $2.19 \%$ \\
\hline 43 & $3.13 \%$ & $3.13 \%$ & $3.13 \%$ \\
\hline 44 & $0.98 \%$ & $2.98 \%$ & $1.98 \%$ \\
\hline 45 & $0.29 \%$ & $0.29 \%$ & $0.29 \%$ \\
\hline 68 & $1.95 \%$ & $1.95 \%$ & $1.95 \%$ \\
\hline 69 & $1.21 \%$ & $1.21 \%$ & $1.21 \%$ \\
\hline 70 & $3.33 \%$ & $1.33 \%$ & $2.33 \%$ \\
\hline 71 & $8.39 \%$ & $6.39 \%$ & $7.39 \%$ \\
\hline 72 & $7.65 \%$ & $5.65 \%$ & $6.65 \%$ \\
\hline 73 & $-0.26 \%$ & $-2.26 \%$ & $-1.26 \%$ \\
\hline 74 & N/A & N/A & N/A \\
\hline 75 & $-4.68 \%$ & $-2.68 \%$ & $-3.68 \%$ \\
\hline 76 & $-3.24 \%$ & $-3.24 \%$ & $-3.24 \%$ \\
\hline 77 & $-1.63 \%$ & $0.37 \%$ & $-0.63 \%$ \\
\hline 78 & $-0.87 \%$ & $-0.87 \%$ & $-0.87 \%$ \\
\hline 79 & $-1.78 \%$ & $-1.78 \%$ & $-1.78 \%$ \\
\hline 80 & $2.19 \%$ & $2.19 \%$ & $2.19 \%$ \\
\hline 81 & $-3.28 \%$ & $-3.28 \%$ & $-3.28 \%$ \\
\hline 82 & $0.24 \%$ & $0.24 \%$ & $0.24 \%$ \\
\hline
\end{tabular}

In table 4 it can be observed that 14 cases out of the 22 presented have obtained both extension of the laminar region and contraction of the turbulent region, having in effect an enlarged transition region. The maximum extension was obtain for case 71, at Mach 0.2 , angle of attack $1.5^{\circ}$ and aileron deflection $4^{\circ}$ down, where the laminar extension is $8.39 \%$ of the chord and the turbulent region contraction is $6.39 \%$ of the chord, closely followed by case 72 . The other 7 cases, mostly for the wing with aileron deflection up, have obtained a contraction of the transition region.

In order to better visualize the results presented in table 4, figures 18 to 20 (a) present the comparison between the experimental unmorphed (original) and morphed transition intervals, while figures 18 to 20 (b) present the comparison between the numerical and experimental unmorphed (original) transition, in order to estimate the degree of accuracy of the numerical analysis. The accuracy level of the numerical values was calculated as an absolute difference between the numerically calculated transition and the closest boundary of the experimental transition interval. It was considered that if the numerical transition was situated inside the experimental transition region, the error would be considered 0 . 


$$
T r_{\text {error }}=T r_{\text {numerical }}-T r_{\text {experimental_upper_boundary }}
$$

Figure 18(a) shows the unmorphed (original) and morphed transition IR experimental results for cases C39 to C45 (Mach number of 0.15 , no aileron deflection and angles of attack between 0.75 and $3^{\circ}$ ).

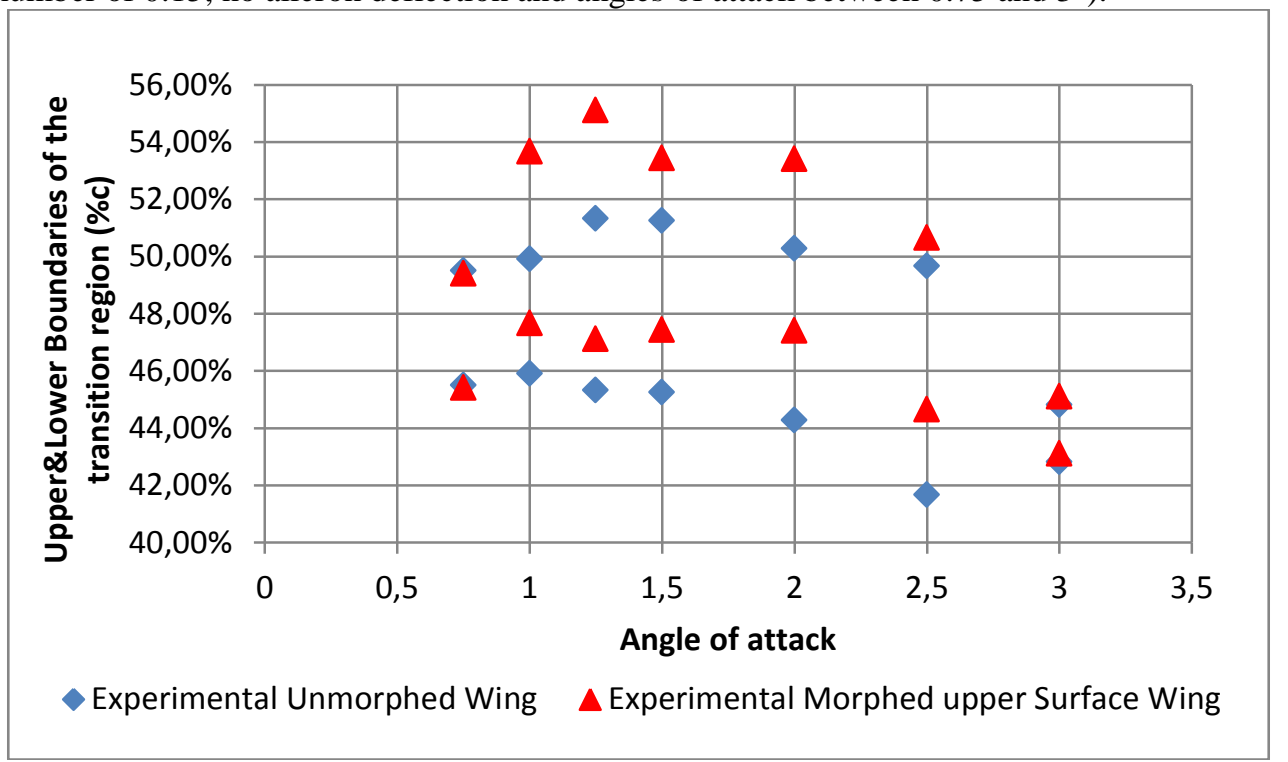

Figure 18(a) Comparison between unmorphed (Original) and morphed IR experimental transition detection for the station located at $40 \%$ of the span for cases C39-C45

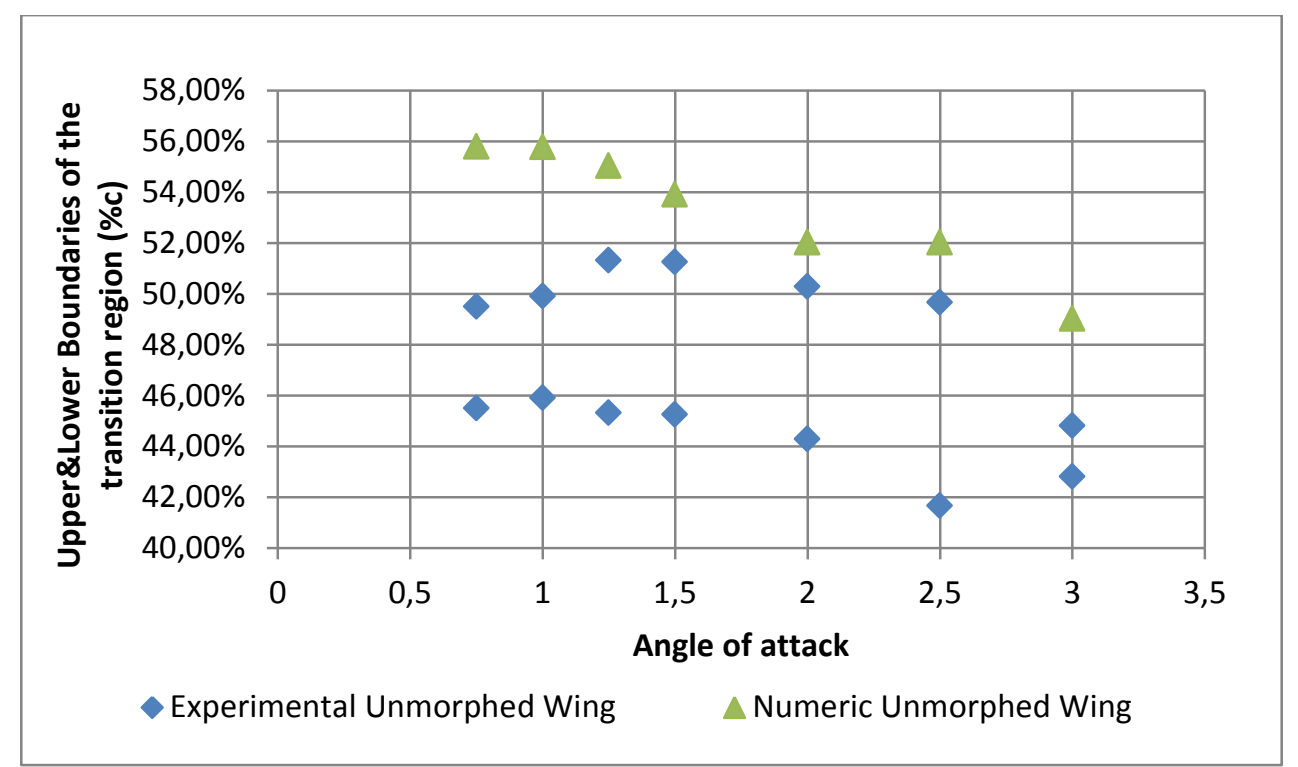

Figure 18(b) Comparison between numerical and IR experimental transition detection for the station located at $40 \%$ of the span for cases C39-C45 - unmorphed (original) state of the wing

In Figure 18(b), it can be seen that a reasonable agreement exists between the experimental and the numerically determined transition point location at the pressure sensors section for the un-morphed (original) wing. For these cases (C39 to C45, with no aileron deflection), the un-morphed (original) wing error is around $6 \%$ of the local chord.

For the morphed geometries results the agreement between the numerical and IR transition positions is slightly better than for the un-morphed wing, with the average error being approximately $5 \%$ of the local chord.

As presented in table 4, Figure 18(a) shows that the IR experimental results show a successful improvement of laminar flow for the section of interest. The transition is delayed towards the trailing edge by $3-4 \%$ of the chord. 
Figure 19(a) shows the unmorphed (original) and morphed transition IR experimental results for cases C68 to $\mathrm{C} 73$ (Mach number of $0.20,4^{\circ}$ downwards aileron deflection and angles of attack between 0 and $2.5^{\circ}$ ).

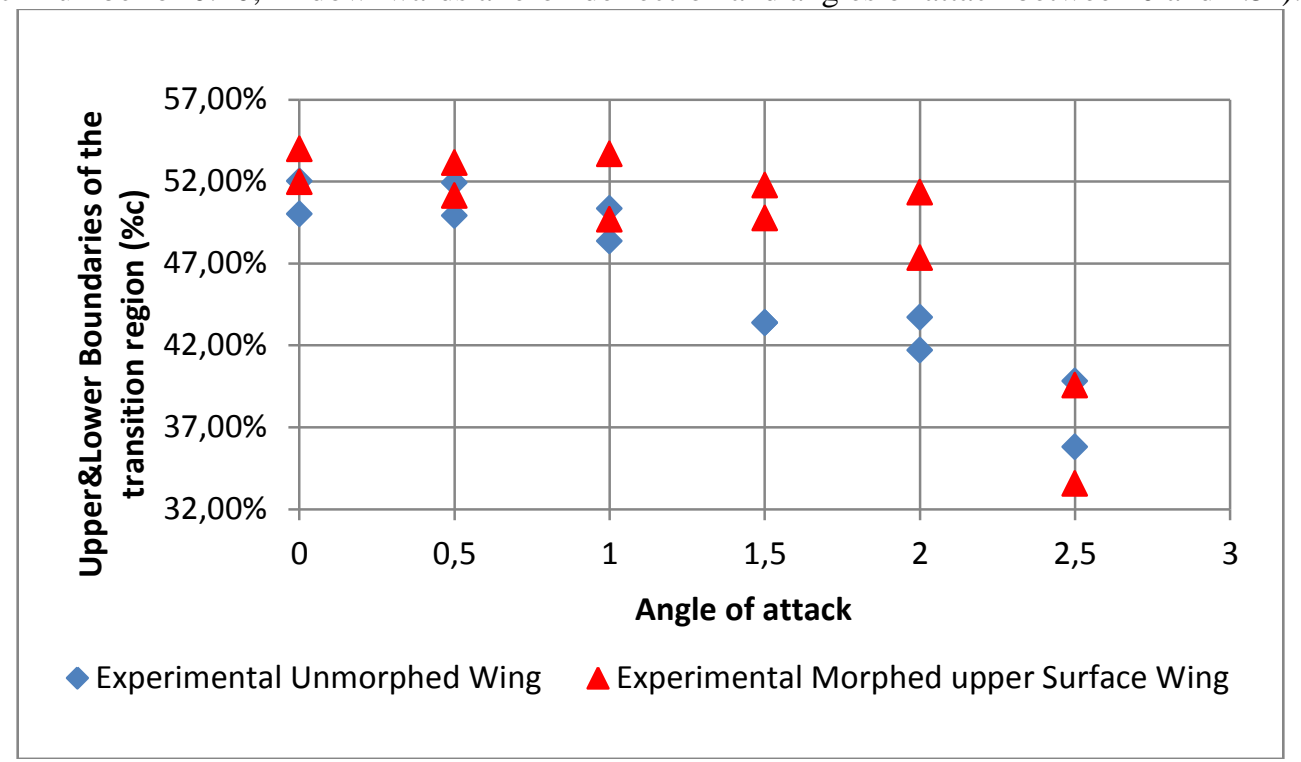

Figure 19(a) Comparison between unmorphed (original) and morphed IR experimental transition detection for the station located at $40 \%$ of the span for cases C68-C73

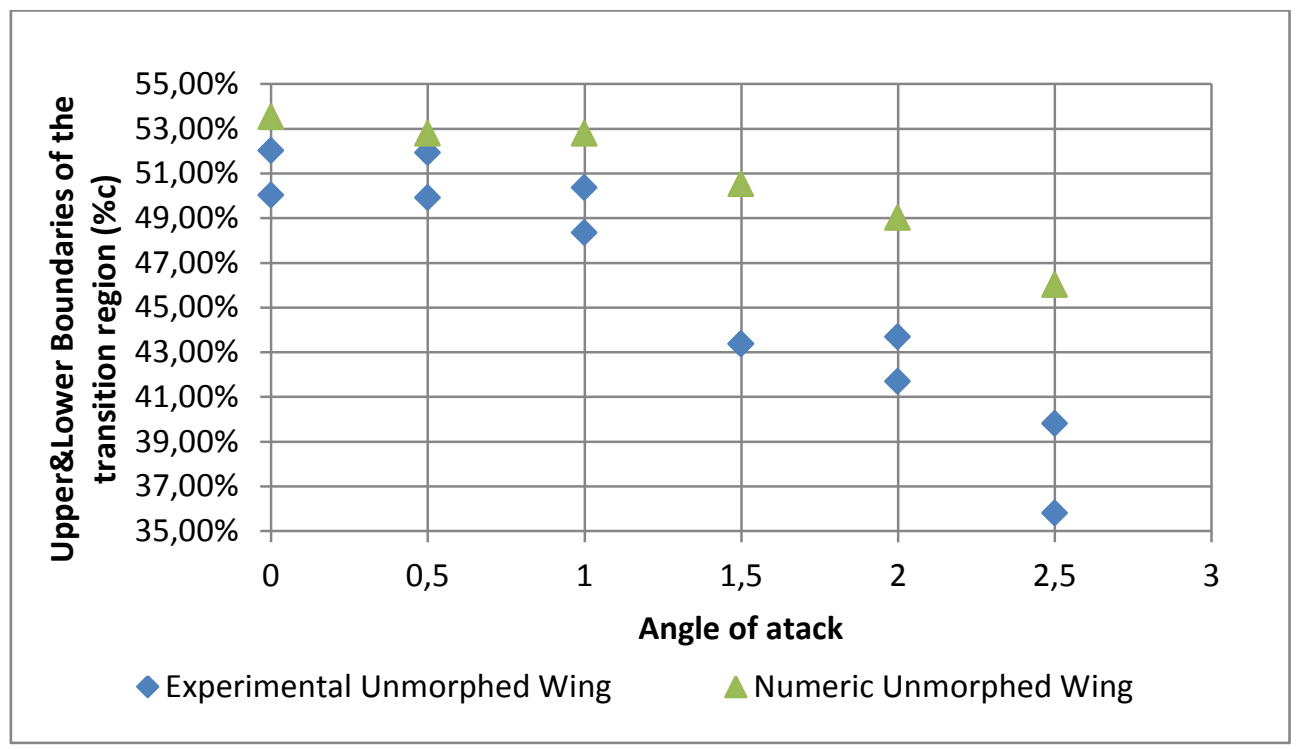

Figure 19(b) Comparison between numerical and IR experimental transition detection for the station located at $40 \%$ of the span for cases C68 - C73 - unmorphed (original) state of the wing

In Figure 19 (b) (cases C68 to C73, with a $4^{\circ}$ aileron deflection), for angles of attack smaller than $1^{\circ}$, there is a very good agreement between numerical versus experimental results obtained for the un-morphed (original) wing. The discrepancy is seen to increase for angles of attack higher than $1.5^{\circ}$, as the experimental measurements show an early shift of the transition occurrence towards the wing leading edge. Again, a successful improvement of laminar flow is observed, with delays of approximately $8 \%$ of the chord obtained for two angles of attack values $\left(1.5^{\circ}\right.$ and $\left.2^{\circ}\right)$. The unmorphed (original) geometries presented in Figure 19 show a good level of agreement between numerical and IR experimental results, with average errors of 3-4\% of the chord. Similar results were obtained for the morphed configurations.

In Figure 20, the experimental and numerical transition location detection for cases C74 to C82 (Mach number of $0.20,4^{\circ}$ upwards aileron deflection, and angles of attack between 0 and $5^{\circ}$ ) is presented for both un- 
morphed (original) and morphed wing geometries. No IR experimental data was available for cases $\mathrm{C} 74\left(0^{\circ}\right.$ angle of attack).

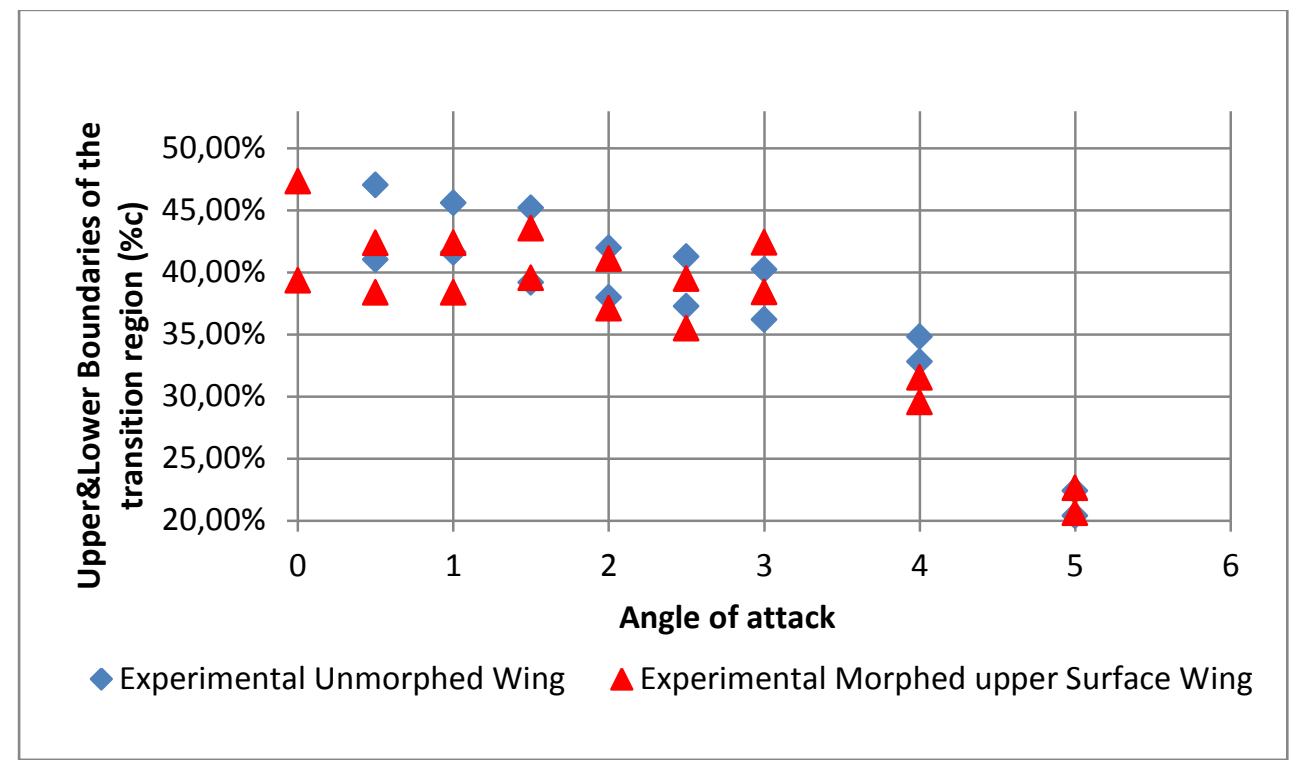

Figure 20(a) Comparison between unmorphed (original) and morphed IR experimental transition detection for the station located at $40 \%$ of the span for cases C74-C 82

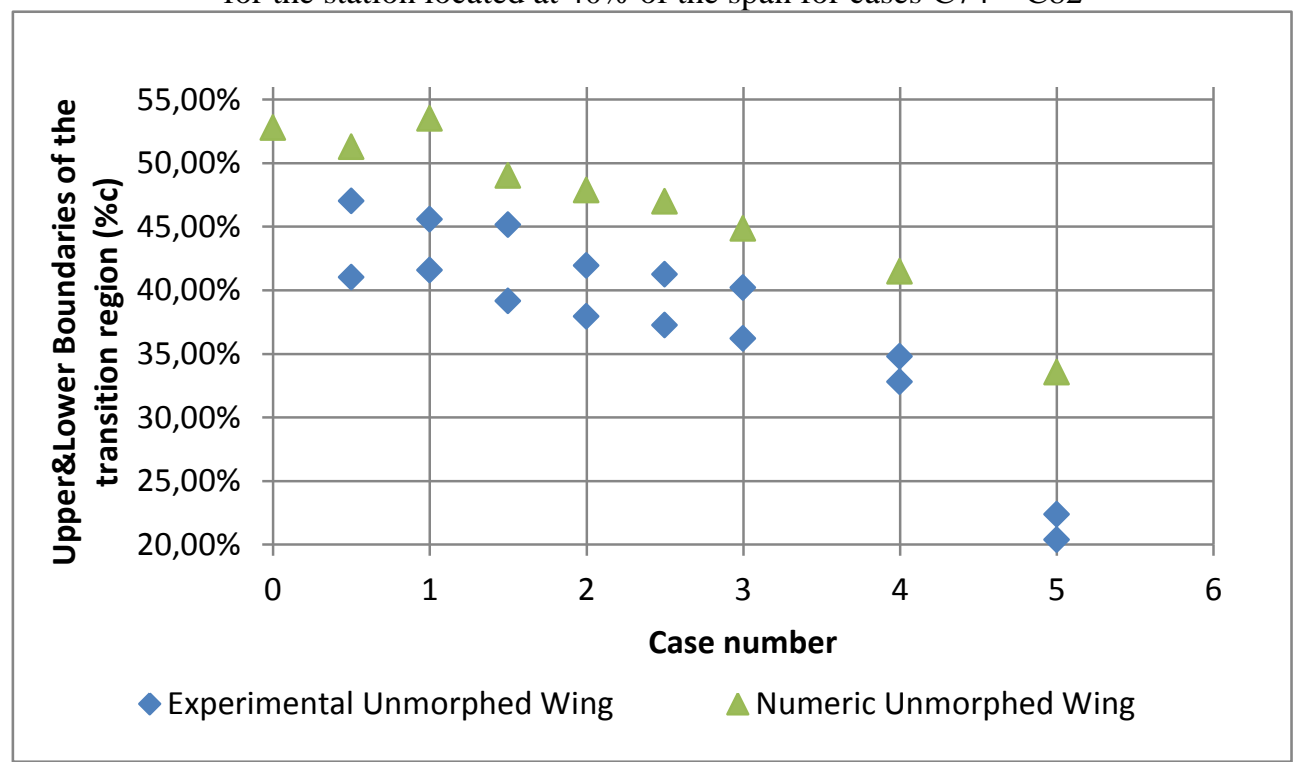

Figure 20(b) Comparison between numerical and IR experimental transition detection

for the station located at $40 \%$ of the span for cases C74 - C 82 - unmorphed (original) state of the wing

For cases C74 to C82 (-4 aileron deflection), presented in Figure 17, there is a good agreement between the IR data and the numerical results for the un-morphed (original) wing (transition position errors of less than 5\% of the chord).

With the exception of case 80, the laminar flow delay predicted by the numerical results is not observed in the IR measurements.

\subsubsection{Pressure coefficient distribution comparisons}

A comparison between the experimental and numerical pressure coefficient distributions for the section located at $40 \%$ of the wing span is presented in Figures 21 to 24, for the following 4 cases: C40 (Mach number of 0.15, angle of attack of $1^{\circ}$, and no aileron deflection), C68 (Mach number of 0.20 , angle of attack of $0^{\circ}$, and $4^{\circ}$ aileron deflection) and for C79 and C82 (Mach number of 0.20 , angles of attack of $2.5^{\circ}$ and $5^{\circ}$, and $-4^{\circ}$ aileron deflection). 
Very good agreement exits between numerical predictions and the wind tunnel test measurements for the two sets of results given by case $\mathrm{C} 40$ and C 68 (Figures 21 and 22). The influence of the upper skin shape change can be observed from the differences between the un-morphed/original (left) and morphed (right) pressure coefficient distributions, for the chordwise interval between $25 \%$ and $60 \%$ of the chord. The skin morphing extends the region where the air accelerates over the upper surface, thus creating more favourable conditions for laminar flow, this effect being clearly visible in the two figures.

For cases C79 and C82 (shown in Figures 23 and 24), a small difference exists in the upper surface pressure coefficient up to $50 \%$ of the chord, and very good agreement exists between the numerical and experimental results for the aileron, rigid lower skin and the upper surface downstream of 50\% of the chord. Once again, the influence of the morphing skin is clearly observable by comparing the left (un-morphed/original) and right (morphed) pressure distributions on both figures.

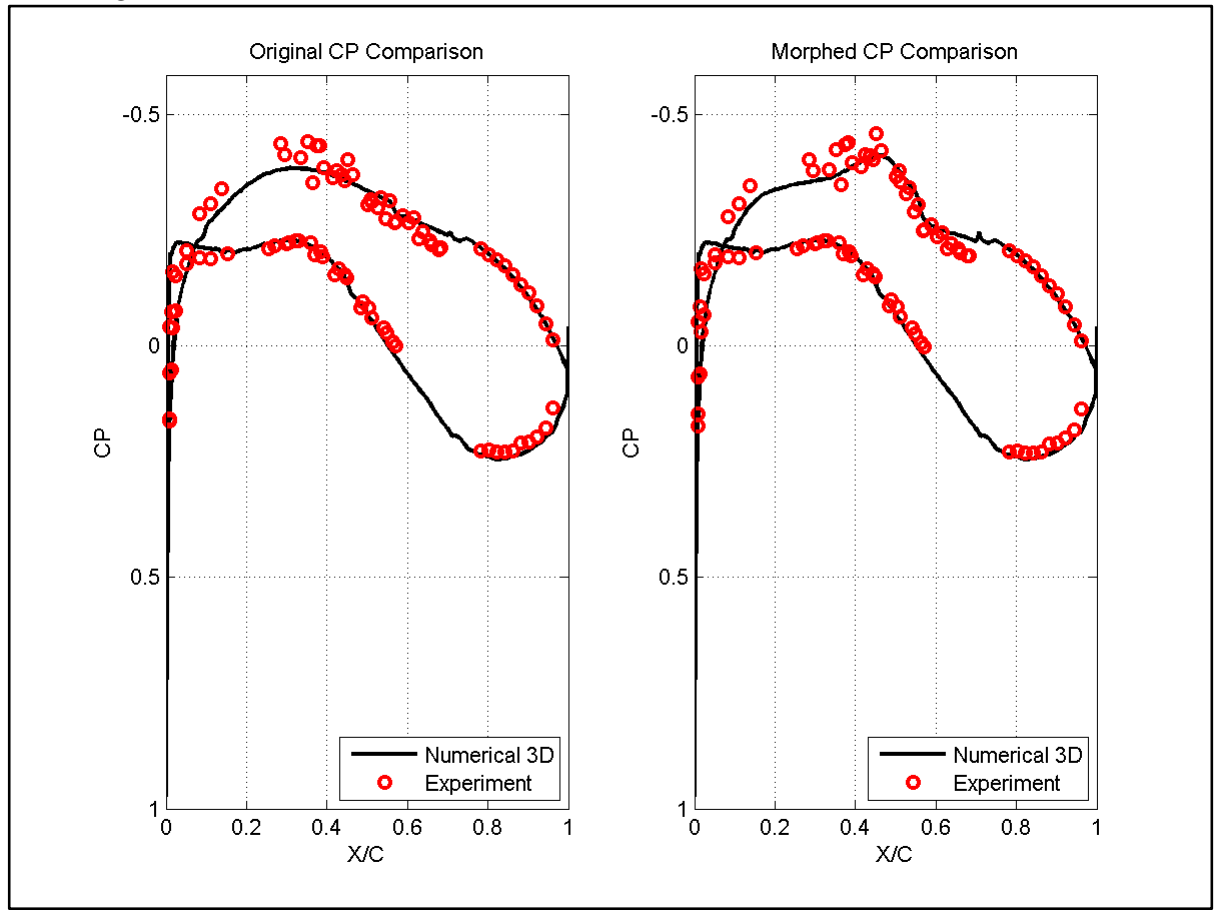

Figure 21 Comparison of experimental versus numerical pressure coefficient distribution for case $\mathrm{C} 40$ corresponding to un-morphed/original (left) and morphed (right) wing 


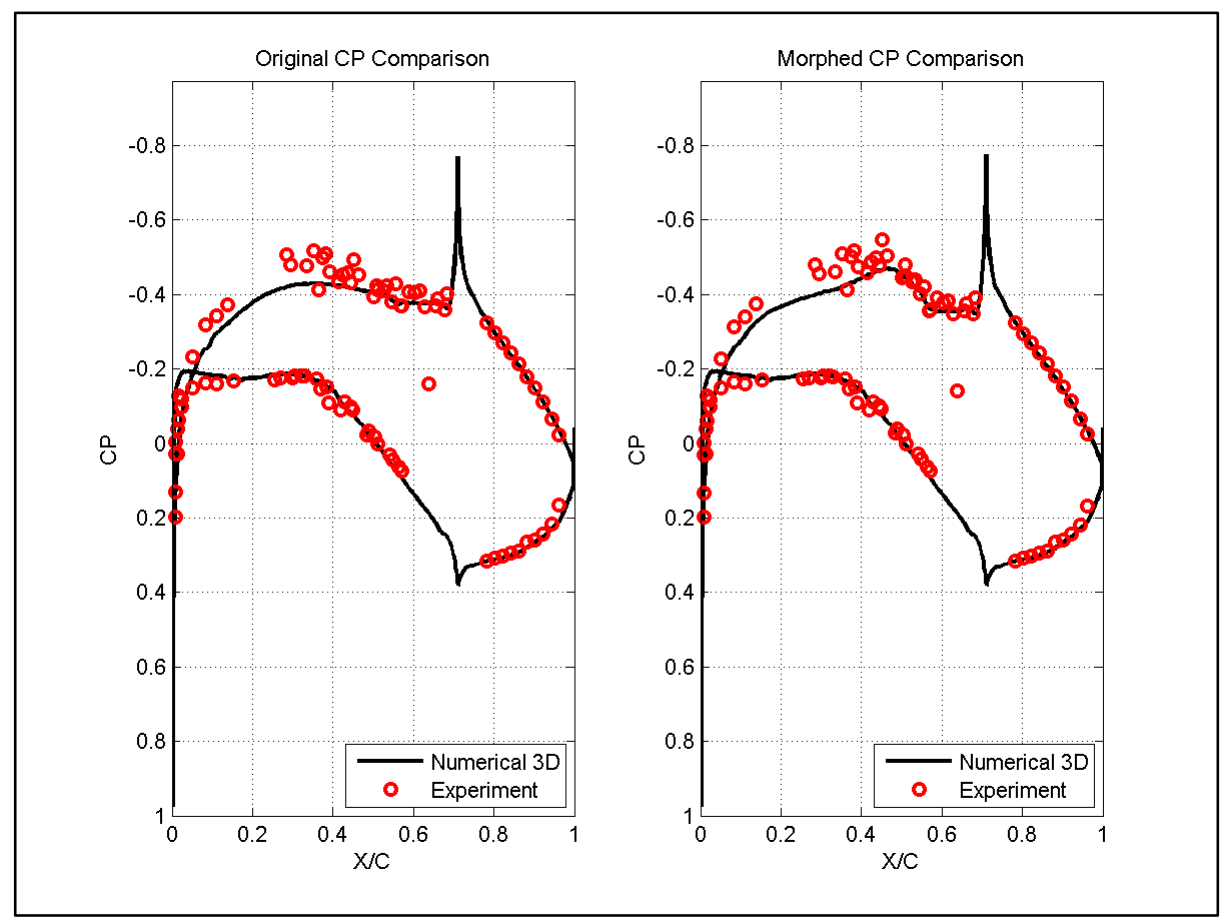

Figure 22 Comparison of experimental versus numerical pressure coefficient distribution for case C68 corresponding to un-morphed/original (left) and morphed (right) wing

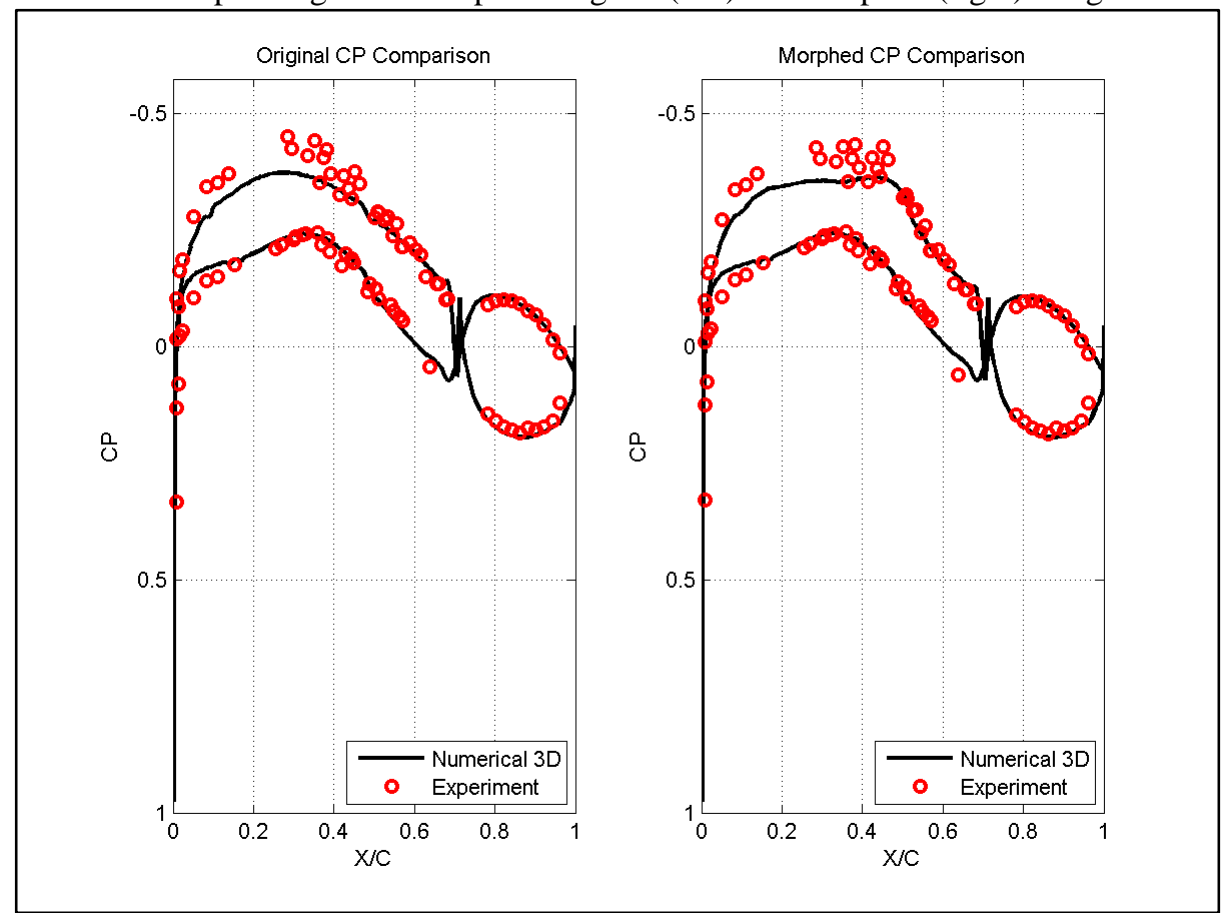

Figure 23 Comparison of experimental versus numerical pressure coefficient distribution for case C79 corresponding to un-morphed/original (left) and morphed (right) wing 


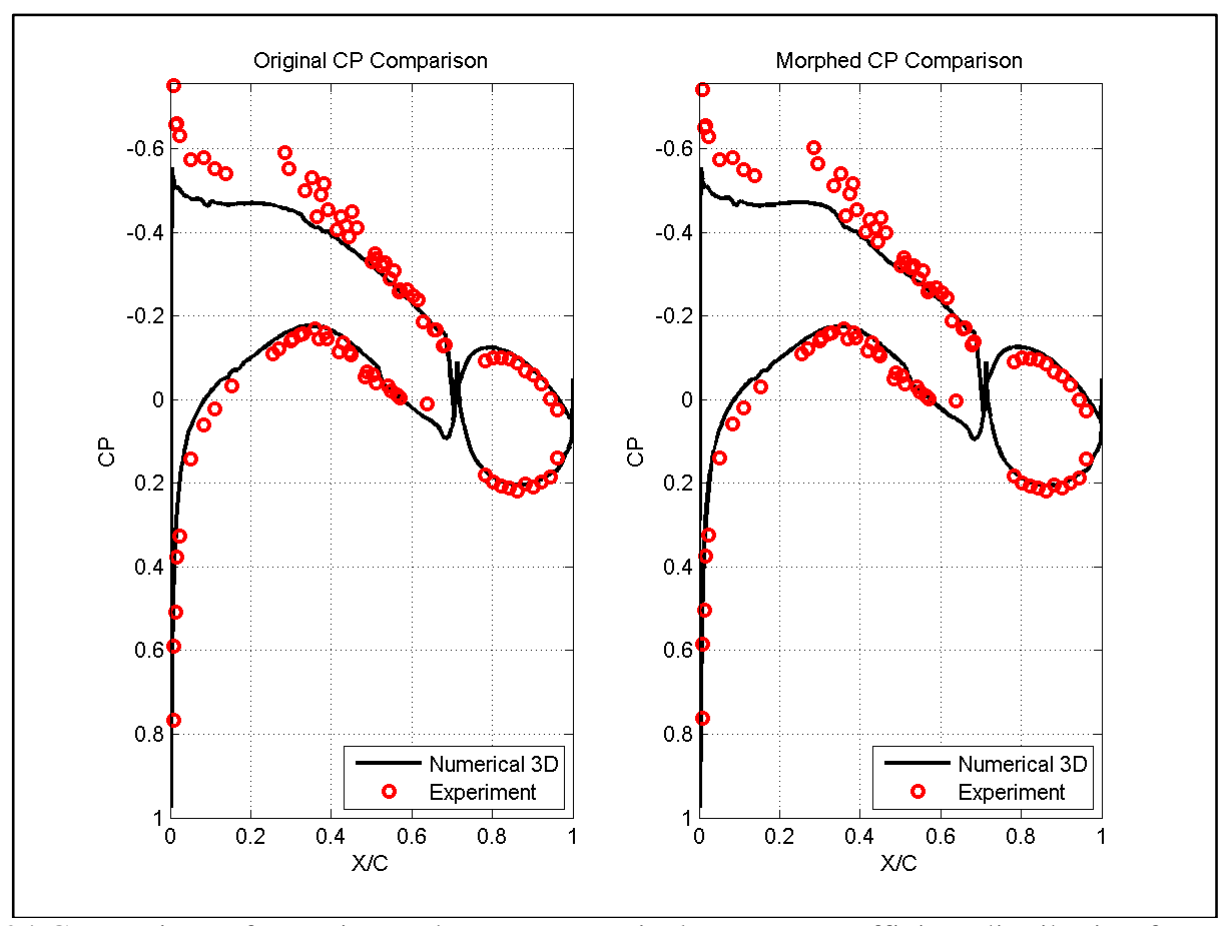

Figure 24 Comparison of experimental versus numerical pressure coefficient distribution for case C82 corresponding to un-morphed/original (left) and morphed (right) wing

\subsection{Results for the third set of wind tunnel tests - Wing equipped with morphing upper surface skin and morphing aileron}

During the third set of wind tunnel tests, 49 flight cases were tested for the wing demonstrator equipped with morphing upper-surface and morphing aileron. For all these flight cases, the optimization was performed prior to the wind tunnel tests, and the optimization objectives were the delay of the flow transition from laminar to turbulent states, and the reduction of the drag coefficient through use of both upper surface morphing and aileron morphing. Table 5 presents seven (7) of these flight cases, that were tested during the third set of wind tunnel tests.

Table 5. Flight cases tested during the third set of wind tunnel tests

\begin{tabular}{|c|c|c|c|c|c|c|c|}
\hline \multirow{2}{*}{ Mach } & \multirow{2}{*}{ Delta [ $\left.{ }^{0}\right]$} & \multicolumn{7}{|c|}{ Angle of Attack [ $\left.{ }^{0}\right]$} \\
\cline { 3 - 8 } & & -1.5 & -1 & -0.5 & 0 & 0.5 & 1 \\
\hline 0.15 & -4.01 & - & - & - & - & C08 & - \\
\hline 0.15 & -1.13 & - & - & $\mathrm{C} 11$ & - & - & - \\
\hline 0.2 & 0.03 & - & - & - & - & $\mathrm{C} 36$ & $\mathrm{C} 25$ \\
\hline 0.2 & -0.24 & $\mathrm{C} 29$ & $\mathrm{C} 30$ & $\mathrm{C} 31$ & - & - & - \\
\hline
\end{tabular}

Table 5a. Actuators' displacements for flight cases presented in Table 5

\begin{tabular}{|c|c|c|c|c|}
\hline Case & Actutator $\mathbf{( m )}$ & Actuator $\mathbf{m}(\mathbf{m})$ & Actuator3 $(\mathbf{m})$ & Actuator4 $(\mathbf{m})$ \\
\hline 8 & $-1.96 \mathrm{E}-03$ & $-9.84 \mathrm{E}-04$ & $-1.74 \mathrm{E}-03$ & $-8.74 \mathrm{E}-04$ \\
\hline 11 & $-9.78 \mathrm{E}-04$ & $1.67 \mathrm{E}-03$ & $-8.68 \mathrm{E}-04$ & $1.49 \mathrm{E}-03$ \\
\hline 25 & $-4.16 \mathrm{E}-04$ & $2.51 \mathrm{E}-03$ & $-3.69 \mathrm{E}-04$ & $2.23 \mathrm{E}-03$ \\
\hline 29 & $-3.97 \mathrm{E}-04$ & $2.17 \mathrm{E}-03$ & $-3.52 \mathrm{E}-04$ & $1.92 \mathrm{E}-03$ \\
\hline 30 & $6.56 \mathrm{E}-05$ & $2.66 \mathrm{E}-03$ & $5.82 \mathrm{E}-05$ & $2.37 \mathrm{E}-03$ \\
\hline
\end{tabular}




\begin{tabular}{|l|c|c|c|c|}
31 & $1.66 \mathrm{E}-03$ & $3.21 \mathrm{E}-03$ & $1.47 \mathrm{E}-03$ & $2.85 \mathrm{E}-03$ \\
\hline 36 & $-3.97 \mathrm{E}-04$ & $2.17 \mathrm{E}-03$ & $-3.52 \mathrm{E}-04$ & $1.92 \mathrm{E}-03$ \\
\hline
\end{tabular}

In order to ensure that the aileron was morphed to the desired shape, the experimental pressure distribution of the wing demonstrator with both its upper surface and aileron actively morphed was compared with the equivalent numerical pressure distribution.

Figures 25 to 28 present the comparison between the numerical and experimental pressure distribution of the wing tip demonstrator with both upper surface and aileron actively morphing for some of the cases from Table 5 . The other cases showed similar level or numerical precision when compared with the experimental data. It can be observed that the two pressure distributions, numerical and experimental, have a very good match, which shows that the aileron had obtained the desired shape during wind tunnel tests, and that the numerical predictions were close to the experimental results.

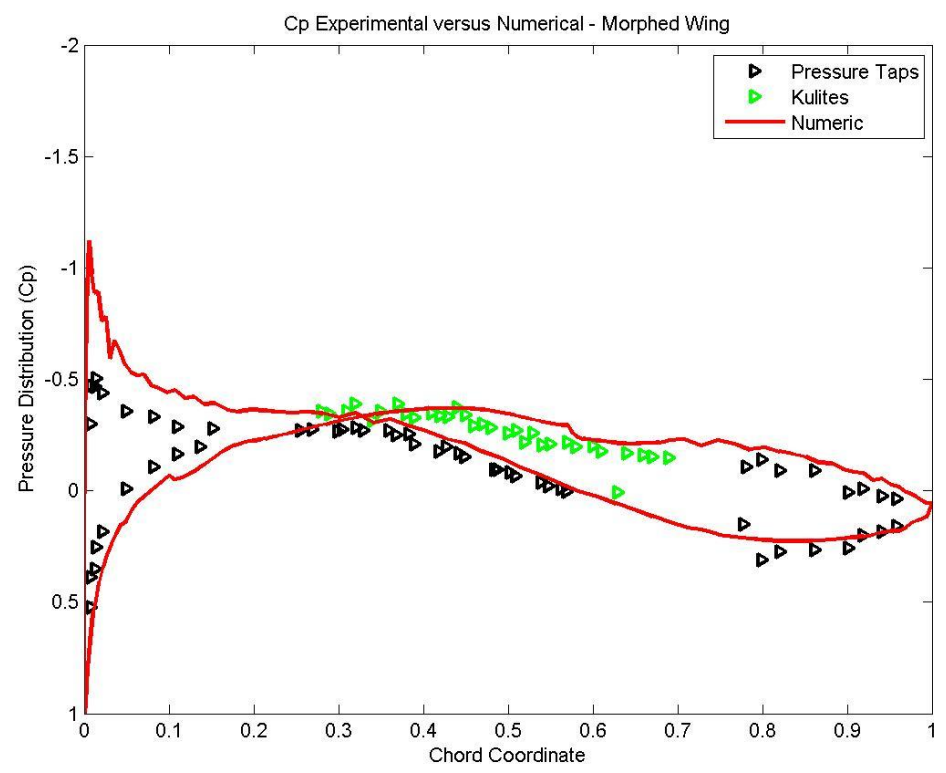

Figure 25 Numerical versus Experimental Pressure Distribution for Case 8

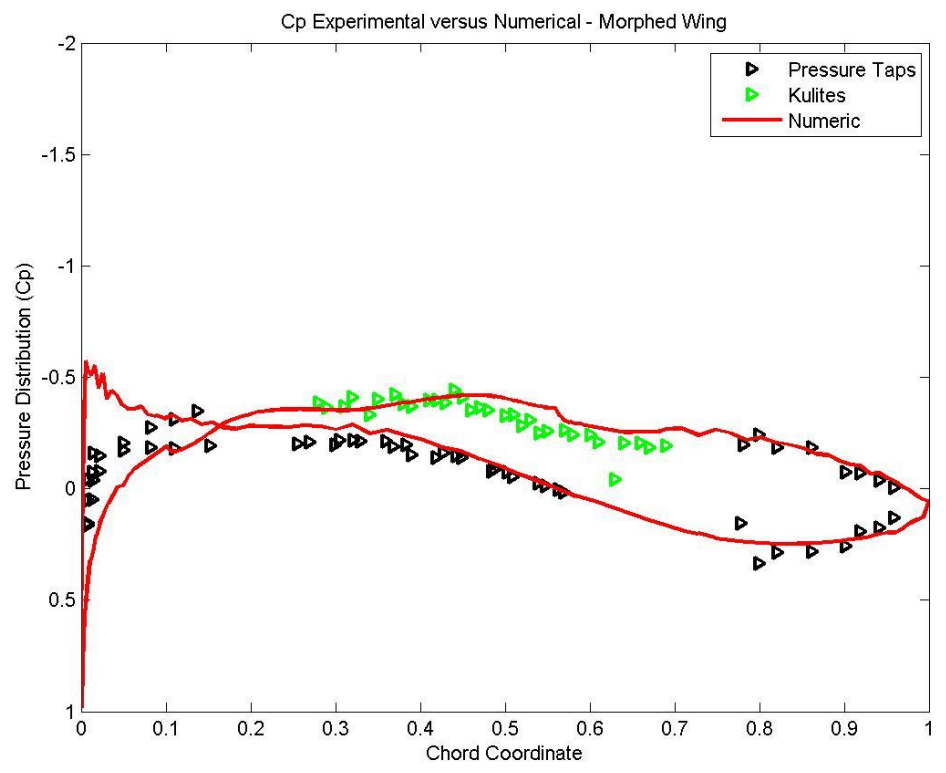


Figure 26 Numerical versus Experimental Pressure Distribution for Case 29

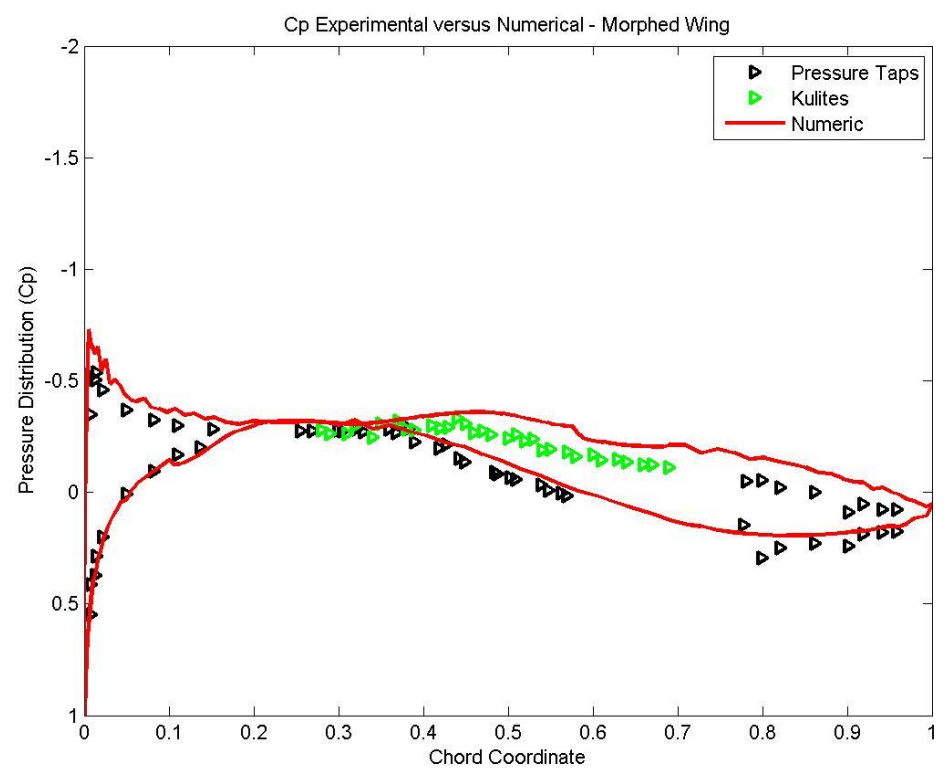

Figure 27 Numerical versus Experimental Pressure Distribution for Case 30

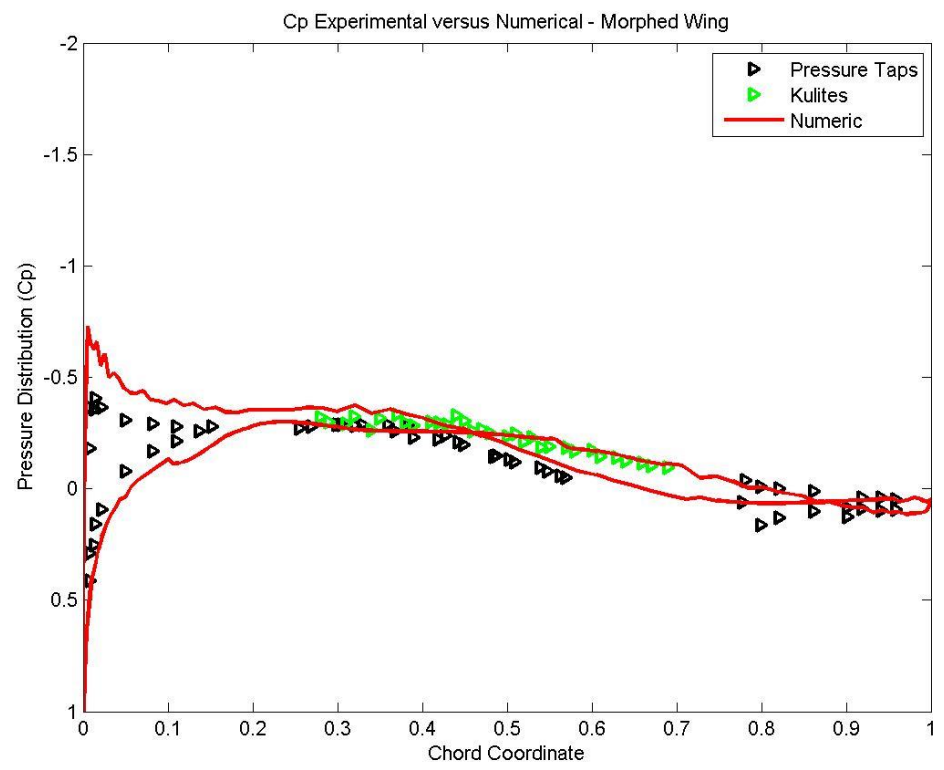

Figure 28 Numerical versus Experimental Pressure Distribution for Case 31

\subsubsection{Experimental transition optimization comparison}

In order to evaluate the optimization success of the wing tip demonstrator equipped with morphing upper surface and morphing aileron, the experimental transition region of the morphed wing tip demonstrator (both upper surface and aileron) was compared to the experimental transition of the un-morphed (original) wing tip demonstrator. The experimental transition region was provided by the Infra-Red Thermography data that was recorded during each of the flight case wind tunnel testing.

All the cases presented in Table 5 have obtained a positive extension of the laminar region coupled with a positive contraction of the turbulent region. For their calculation, equations 10 and 11 were used. 


$$
\begin{aligned}
& \tau=\text { Morphed }_{U B}-\text { Unmorphed }_{U B} \\
& U B=\text { upper }- \text { boundary } \\
& \lambda={\text { Morphed } T r_{L B}-\text { UnmorphedTR }}_{L B} \\
& L B=\text { lower }- \text { boundary }
\end{aligned}
$$

Table 6 presents the values of extension of the laminar region ( $\lambda)$, contraction of the turbulent region $(\tau)$, and the average transition extension of the un-morphed (original) and morphed transition region for the seven cases from Table 5.

Table 6 Presentation of $(\boldsymbol{\tau})$ and $(\lambda)$ parameters for each of the flight cases from Table 5

\begin{tabular}{|c|c|c|c|}
\hline Case No & $\begin{array}{c}\text { Extension of the Laminar } \\
\text { region }(\% \text { of chord) }(\lambda)\end{array}$ & $\begin{array}{c}\text { Transition Region average } \\
(\% \text { of chord) }\end{array}$ & $\begin{array}{c}\text { Contraction of the turbulent } \\
\text { region }(\% \text { of chord) }(\tau)\end{array}$ \\
\hline 8 & $2.84 \%$ & $3.84 \%$ & $4.84 \%$ \\
\hline 11 & $0.92 \%$ & $1.92 \%$ & $2.92 \%$ \\
\hline 25 & $6.43 \%$ & $6.43 \%$ & $6.43 \%$ \\
\hline 29 & $1.80 \%$ & $0.80 \%$ & $-0.20 \%$ \\
\hline 30 & $3.87 \%$ & $2.87 \%$ & $1.87 \%$ \\
\hline 31 & $1.71 \%$ & $1.71 \%$ & $1.71 \%$ \\
\hline 36 & $1.66 \%$ & $2.66 \%$ & $3.66 \%$ \\
\hline
\end{tabular}

Flight case 29 gives a small negative contraction of the turbulent region $\tau$ that is counterbalanced by almost $2 \%$ of the chord of laminar region extension.

The other flight cases gave an extension of the laminar region ( $\lambda$ ) of up to $6.5 \%$ of the chord, and a contraction of the turbulent region $(\tau)$ of up to $5 \%$ of the chord.

Figure 29 presents the transition region for the un-morphed (original) and morphed wing for all the cases discussed above. In this figure, a delay of the transition region between un-morphed and morphed states can be observed towards the trailing edge section of the wing. This transition delay is due to having both the upper surface skin and aileron morphing at the same time. 


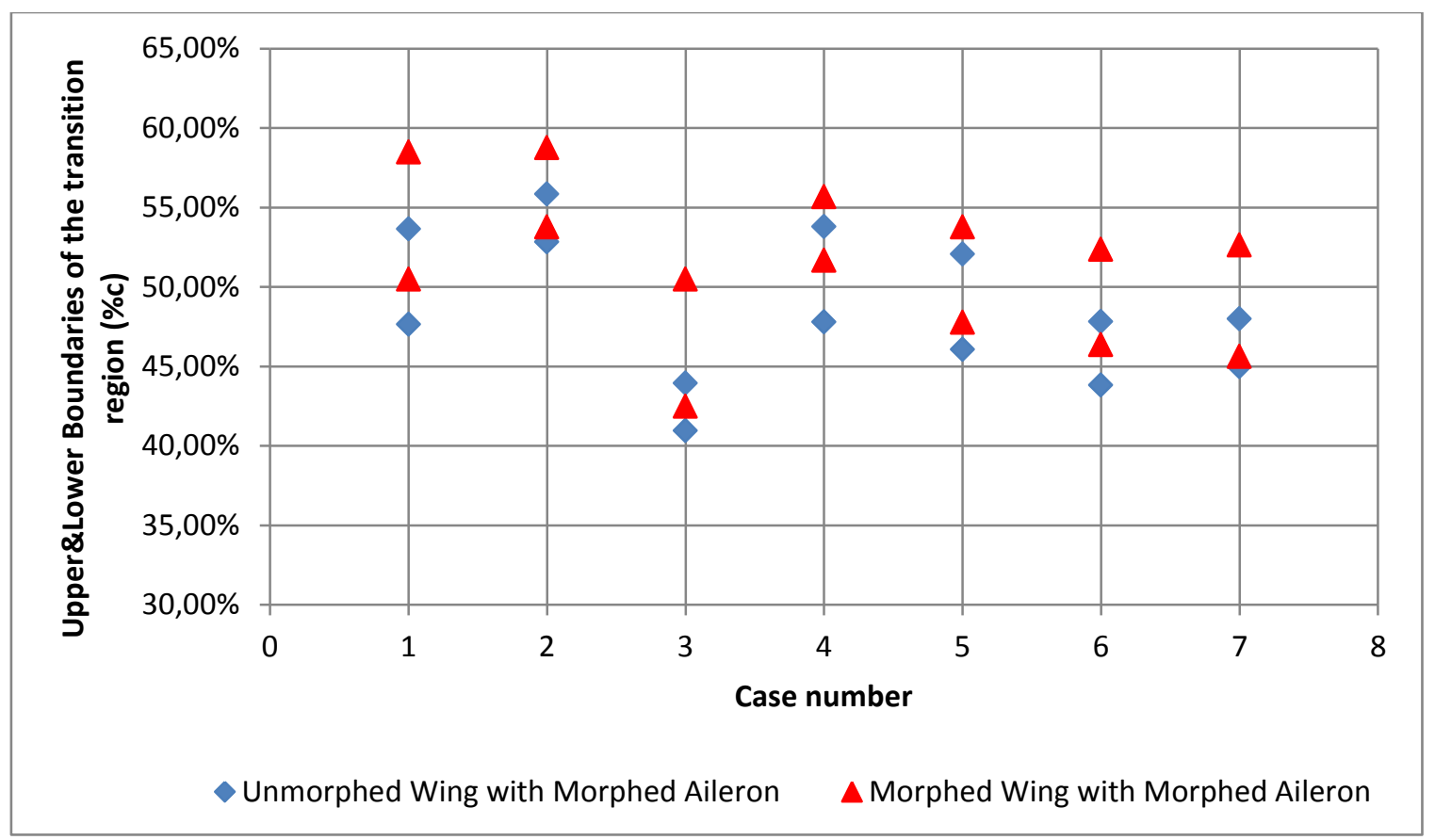

Figure 29 Comparison between un-morphed and morphed states of the wing's upper surface when aileron is morphed - experimental data

The influence of the morphing aileron and morphing wing upper surface were observed on the behaviour of the boundary layer through extension of the laminar state of the flow, but they also influenced the behaviour of the drag coefficient of the wing. Figure 30 presents the effects that the morphing of the wing upper surface and of the aileron had on the drag, as a comparison between the morphed and un-morphed states of the wing tip. Figure 31 presents the relative difference between the two states of the wing for the drag reduction, while Figure 32 presents the influence morphing has had on the Lift-Drag relation. All coefficients are presented in counts, where 1 count $=$ $1 \mathrm{e}^{-3}$.

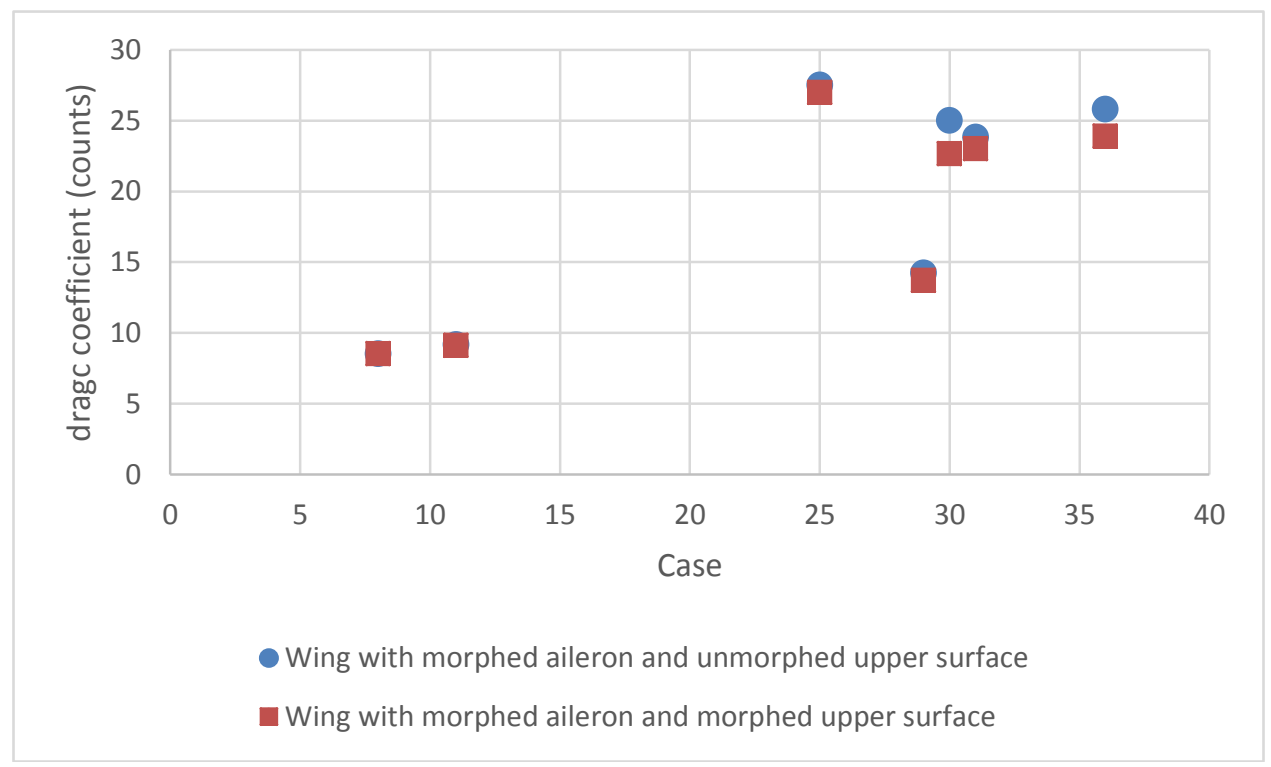

Figure 30 Effect of the morphing upper surface and morphing aileron on the drag coefficient 


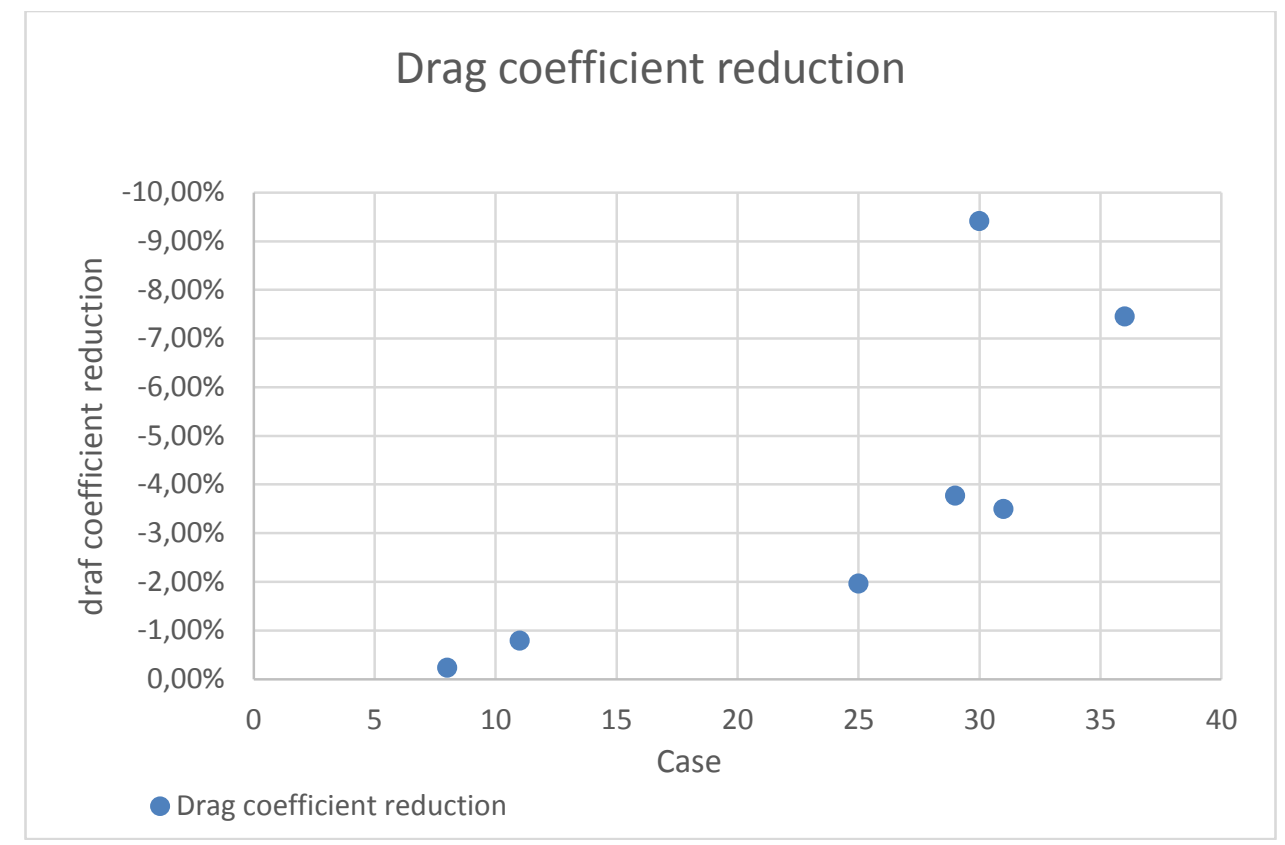

Figure 31 Relative value of the drag coefficient reduction

The relative drag reduction was calculated as shown in equation (9):

$$
C_{D \text { reduction }}=\frac{\left(C_{D \text { morphed }}-C_{D \text { unmorphed }}\right)}{C_{D \text { unmorphed }}} \cdot 100
$$

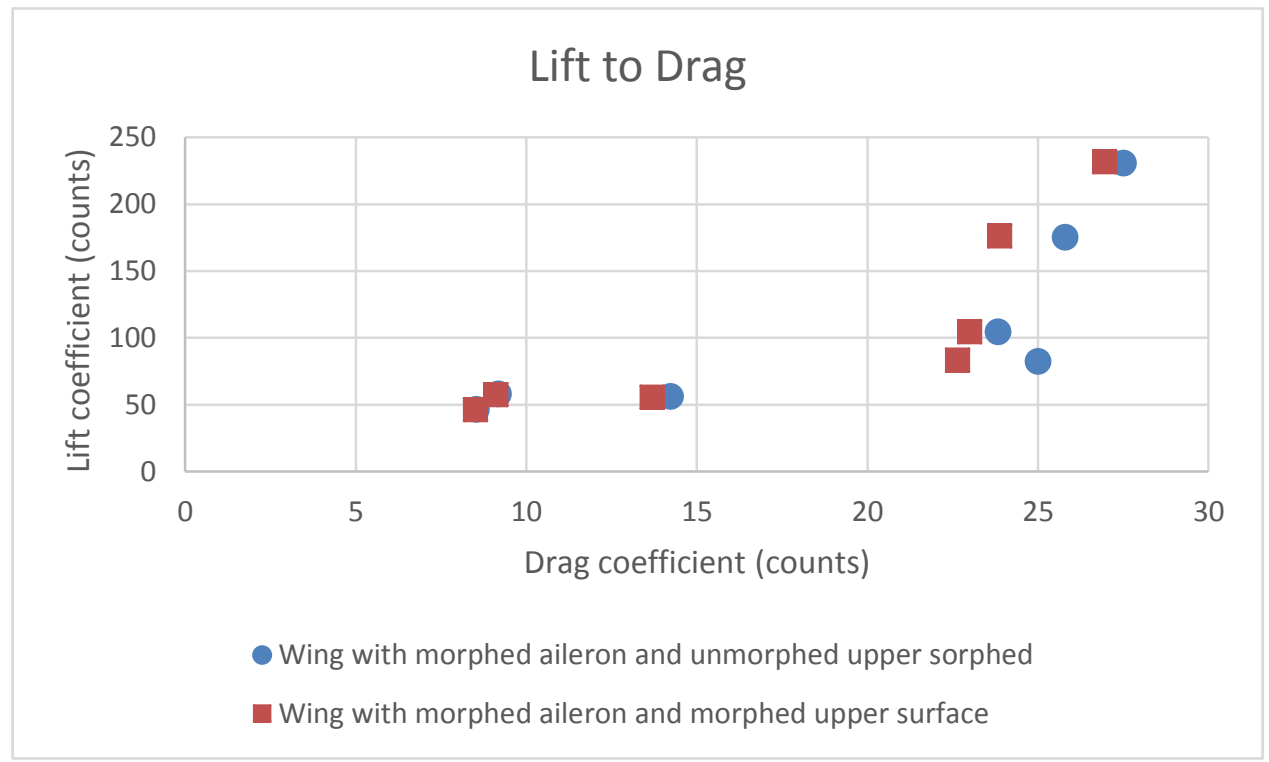

Figure 32 Lift versus Drag comparison between morphed and un-morphed states

Based on the experimental results, the coupled morphing of upper surface and aileron has achieved a drag coefficient reduction of up to $9.5 \%$, even when the aileron deflections were small. This fact demonstrates that a smoother slope for the wing camber line, even at small deflections, has a high impact on the wing's performances. 
Although, only 7 cases were presented in this paper, from the 49 cases studied during the third set of tests, 32 have obtained both the extension of the flow's laminar state and reduction of the drag coefficient. These results show the promising performances of an intelligent wing with both upper surface morphing and aileron morphing.

\section{Conclusions}

In the present paper, the numerical and experimental results of a new wing tip equipped with morphing upper surface, conventional aileron and morphing aileron were presented. The results were obtained during the second and third sets of wind tunnel tests that took place at the NRC subsonic wind tunnel in Ottawa.

The morphing wing tip was manufactured and fitted with a composite material upper skin. Twodimensional optimizations were performed with the aim of controlling the extent of the laminar flow region, and the resulting skin shapes were scanned using high-precision photogrammetry. The scanning had the aim to verify that the expected shapes (calculated using the optimization algorithm) were obtained by manufacturing the wing tip. A grid convergence study was performed to determine the optimal mesh refinement required by the numerical transition model. Subsonic wind tunnel tests were performed at the NRC $2 \mathrm{~m}$ x $2 \mathrm{~m}$ wind tunnel, and the experimental measurements included Infra-Red thermography, pressure sensors measurements and balance loads measurements.

Three series of wind tunnel test cases were analyzed, each case consisted of a combination of angles of attack, Mach number and aileron deflection angle. Comparisons were made between the un-morphed and morphed upper skin shapes, for the transition point location at the station situated at $40 \%$ of the wing span, corresponding to the pressure sensors station. Good agreement was obtained between the numerical and IR results, with an average prediction error of approximately $5 \%$ of the chord. Both the IR measurements and the numerical results have shown that an increase in the laminar flow region was obtained after the optimization. The experimental transition delay was between 3 and $9 \%$ of the chord, while the numerical improvements in transition delay were smaller.

The experimental results from the third set of wind tunnel tests have shown that the morphing aileron was capable of obtaining the desired shape, resulting from the pressure distribution comparison. The objective of flow transition delay was achieved for all the flight cases presented in this paper, with the delay of the transition going obtained at $7 \%$ of the chord.

The laminar flow extension was obtained for a significant percentage of the upper skin span. Pressure coefficient comparisons, between numerical and experimental data, were performed at the $40 \%$ of the span section, and a good match was obtained.

These results show the success of the numerical optimization carried at airfoil level and the possibilities that could be explored with a wing equipped with a morphing upper surface and conventional aileron or for a wing equipped with a morphing upper surface and a morphing aileron wing.

\section{Acknowledgements}

We would like to thank to Bombardier Aerospace, Thales Canada, The Consortium in Research and Aerospace in Canada (CRIAQ), and to the Natural Sciences and Engineering Research Council of Canada (NSERC) for their financial support. Special thanks are dues to our collaborators and leaders in this project: Dr. Patrick Germain and Dr. Fassi Kafyeke from Bombardier Aerospace, Dr. Philippe Molaret from Thales Canada, Mr. Erik Sherwood and his team from DFS-NRC for the wing model design and fabrication and Dr. Eric Laurendeau from Ecole Polytechnique.

\section{Bibliography}

${ }^{1}$ ATAG, (2014) “Aviation: benefits without borders", Report, Air Transport Action Group, http://www.atag.org/. ${ }^{2}$ United States Navy, "F-14 Tomcat fighter fact file”, 5 July 2003, retrieved: 20 January 2007, cited in May 2016

${ }^{3}$ Talay, Th. A., ed. (2003) "Dynamic Longitudinal, Directional, and Lateral Stability", Centennial of Flight Commission, 2003, retrieved: 24 May 2011, cited in May 2016

${ }^{4}$ Bonnema, K. L., \& Smith, S. B., (1998) “AFTI/F-111 mission adaptive wing flight research program”, Report, San Diego, California, pp. $155-161,1988$ 
${ }^{5}$ Sofla, A. Y. N., Meguid, S. A., Tan, K. T., \& Yeo, W. K. (2010). "Shape morphing of aircraft wing: status and challenges". Materials \& Design, 31(3), 1284-1292.

${ }^{6}$ Barbarino, S., Bilgen, O., Ajaj, R. M., Friswell, M. I., \& Inman, D. J. (2011). "A review of morphing aircraft", Journal of Intelligent Material Systems and Structures, 22(9), 823-877.

${ }^{7}$ Gabor, O. S., Koreanschi, A., \& Botez, R. M. (2013). "Optimization of an Unmanned Aerial Systems' Wing Using a Flexible Skin Morphing Wing”, SAE International Journal of Aerospace, 6(2013-01-2095), 115-121.

${ }^{8}$ Gabor, S., Koreanschi, A., \& Botez, R. M. (2014) "Numerical optimization of the S4 Éhecatl UAS airfoil using a morphing wing approach", In American Institute of Aeronautics and Astronautics AIAA 32nd Applied Aerodynamics Conference, 16-20 June 2014, Atlanta, Georgia, USA.

${ }^{9}$ R. Pecora, S. Barbarino, A. Concilio, L. Lecce \& S. Russo, (2011) "Design and Functional Test of a Morphing High-Lift Device for a Regional Aircraft", Journal of Intelligent Material Systems and Structures, vol. 22, no. 10, 2011, pp. 1005-1023.

${ }^{10}$ O. Bilgen, K.B. Kochersberger, E.C. Diggs, A.J. Kurdila \& D.J. Inman, (2007) "Morphing wing Micro-AirVehicles via Macro-Fiber-Composite actuators", Proceedings of 48th AIAA/ASME/ASCE/AHS/ASC Structures, Structural Dynamics and Materials Conference, 23-26 April 2007, Honolulu, HI, AIAA Paper 2007-1785.

${ }^{11}$ O. Bilgen, K.B. Kochersberger \& D.J. Inman, (2009) "Macro-Fiber Composite actuator for a swept wing Unmanned Aerial Vehicle", Special issue on Flight Structures Fundamental Research in the USA, 113:385-395, 2009.

${ }^{12}$ A.M. Pankonien \& D.J. Inman, (2015) "Spanwise morphing trailing edge on a finite wing", Active and Passive Smart Structures and Integrated Systems 2015 Conference, San Diego, CA, USA, 8 March 2015.

${ }^{13}$ Botez, R. M., Molaret, P., \& Laurendeau, E.,(2007) "Laminar flow control on a research wing project presentation covering a three year period", Canadian Aeronautics and Space Institute Annual General Meeting, 2007, Ottawa, Ont., Canada.

${ }^{14}$ Mamou, M, Mébarki, Y., Khalid, M., Genest, M., Coutu, D., Popov, A.V., Sainmont, C., Georges, T., Grigorie, L., Botez, R.M., Brailovski, V., Terriault, P., Paraschivoiu, I., Laurendeau, E., Aerodynamic performance optimization of a wind tunnel morphing wing model subject to various cruise flow conditions, $27^{\text {th }}$ International Congress of the Aeronautical Sciences, Nice, France, $19-24^{\text {th }}$ September 2010

${ }^{15}$ Grigorie, T. L., Popov, A. V., Botez, R. M., Mamou, M., \& Mébarki, Y.,(2010) “A Morphing Wing used Shape Memory Alloy Actuators New Control Technique with Bi-positional and PI Laws Optimum Combination - Part 1: Design Phase.", ICINCO 2010, Proceedings of the 7th International Conference on Informatics in Control, Automation and Robotics, Volume 1, Funchal, Madeira, Portugal, June 15-18.

${ }^{16}$ Grigorie, T. L., Popov, A. V., Botez, R. M., Mamou, M., \& Mébarki, Y.,(2010) “A Morphing Wing used Shape Memory Alloy Actuators New Control Technique with Bi-positional and PI Laws Optimum Combination - Part 2: Experimental Validation.", ICINCO 2010, Proceedings of the 7th International Conference on Informatics in Control, Automation and Robotics, Volume 1, Funchal, Madeira, Portugal, June 15-18

${ }^{17}$ Coutu, D., Brailovski, V., \& Terriault, P., (2009) "Promising Benefits of an Active-Extrados Morphing Laminar Wing", Journal of Aircraft, Vol. 46, No. 2, pp. 730-731, March-April.

${ }^{18}$ Courchesne, S., Popov, A. V., \& Botez, R. M., (2010) "New aeroelastic studies for a morphing wing", 48th AIAA Aerospace Sciences Meeting including The New Horizons Forum and Aerospace Exposition, Orlando, Florida, USA, 2010.

${ }^{19}$ Popov, A.V., Botez, R.M., Grigorie, T. L., Mamou, M., \& Mebarki, Y., (2010) "Real time airfoil optimization of a morphing wing in wind tunnel”, AIAA Journal of Aircraft, Vol. 47(4), pp. 1346-1354, 2010.

${ }^{20}$ Popov. A-V., Labib, M., Fays, J., \& Botez, R.M., (2008) "Closed loop control simulations on a morphing laminar airfoil using shape memory alloys actuators", AIAA Journal of Aircraft, Vol. 45(5), pp. 1794-1803, 2008.

${ }^{21}$ Popov, A.V., Botez, R.M., Grigorie, T. L., Mamou, M., \& Mebarki, Y., (2012) "On-off and proportional-integral controller for a morphing wing. Part 1: Actuation mechanism and control design", Journal of Aerospace Engineering, February 2012; vol. 226, 2: pp. 131-145., first published on November 21, 2011

${ }^{22}$ Grigorie, L. T., \& Botez, R. M., "Adaptive neuro-fuzzy inference system-based controllers for smart material actuator modelling”, Journal of Aerospace Engineering, vol. 223, 6: pp. 655-668. , June 1, 2009

${ }^{23}$ Grigorie, L.T., Botez, R.M., \& Popov, A.-V., "Adaptive neuro-fuzzy controllers for an open loop morphing wing system”, Journal of Aerospace Engineering, Vol. 223(J), pp. 965-975, 2009.

${ }^{24}$ Michaud, F., Joncas, S., \& Botez, R. M. (2013) "Design, Manufacturing and Testing of a Small-Scale Composite Morphing Wing", In 19th International Conference on Composite Materials, Montréal, Québec, Canada, July.

${ }^{25}$ Koreanschi, A., Henia, M. B., Guillemette, O., Michaud, F., Tondji, Y., Gabor, O. S., \& Salinas, M. F. (2016). "Flutter Analysis of a Morphing Wing Technology Demonstrator: Numerical Simulation and Wind Tunnel Testing", INCAS Bulletin, 8(1), 99. 
${ }^{26}$ Kammegne, M. J. T., Nguyen, D. H., Botez, R. M., \& Grigorie, T. L. (2015) “Control validation of a morphing wing in an open loop architecture", AIAA Modeling and Simulation Technologies Conference, Aviation Forum.

${ }^{27}$ Kammegne, Michel Joël Tchatchueng, Hamdi Belhadj, Duc-Hien Nguyen, \& Ruxandra Mihaela Botez. (2015)

"Nonlinear Control Logic for an Actuator to Morph a Wing: Design and Experimental Validation." IASTED Modelling, Identification and Control Conference, 2015.

${ }^{28}$ F. Michaud, "Design and Optimization of a Composite Skin for an Adaptive Wing", Master of Science Thesis, Ecole de technologie superieure, Montreal, Canada, 2014.

${ }^{29}$ R. Pecora, F. Amoroso, M. Magnifico, I. Dimino, A. Concilio, KRISTINA: Kinematic Rib based Structural system for Innovative Adaptive trailing edge, SPIE Smart Structures/NDE, Las Vegas, Nevada (USA) March 2016. Proc. SPIE 9801, Industrial and Commercial Applications of Smart Structures Technologies 2016, 980107 (April 16, 2016); doi:10.1117/12.2218516

${ }^{30}$ I. Dimino, A. Concilio and R. Pecora, Safety and Reliability Aspects of an Adaptive Trailing Edge Device (ATED), 24th AIAA/AHS Adaptive Structures Conference, AIAA SciTech, 4-8 Jan 2016

${ }^{31}$ Barbarino, S., Pecora, R., Lecce, L., Concillio, A., Ameduri, S., \& De Rosa, L., "Airfoil structural morphing based on SMA actuator series: numerical and experimental studies", Journal of Intelligent Material Systems and Structures, Vol. 22, pp. 987-1003, 2001

${ }^{32}$ Ameduri, S., Brindisi, A., Tiseo, B., Concilio, A., \& Pecora, R., (2002) "Optimization and integration of shape memory alloy (SMA) based elastic actuators within a morphing flap architecture", Journal of Intelligent Material Systems and Structures, Vol. 23, issue 4, pp. 381-396, 2002

${ }^{33}$ Diodati, G., Concilio, A., Ricci, S., de Gaspari, A., Liauzun, C., \& Godard, J.L., (2013) "Estimated performance of an adaptive trailing-edge device aimed at reducing the fuel consumption on a medium-size aircraft", Smart Structures/NDE conference, 10-14 March 2013, San Diego, California,USA, 2013

${ }^{34}$ G. Amendola, I. Dimino, M. Magnifico and R. Pecora, (2016), "Distributed actuation concepts for a morphing aileron device", The Aeronautical Journal, Vol. 120, No. 1231, pp. 1365-1385 doi 10.1017/aer.2016.64

${ }^{35}$ Koreanschi, A., Sugar-Gabor, O. \& Botez, R.M. (2016) "Numerical and experimental validation of a morphed wing geometry using Price-Païdoussis wind-tunnel testing". The Aeronautical Journal, 120, pp 757-795 doi:10.1017/aer.2016.30

${ }^{36}$ Gabor, O. S., Koreanschi, A., \& Botez, R. M. (2012) "Low-speed aerodynamic characteristics improvement of ATR 42 airfoil using a morphing wing approach" In IECON 2012-38th Annual Conference on IEEE Industrial Electronics Society (pp. 5451-5456). IEEE.

${ }^{37}$ Koreanschi, A., Şugar Gabor, O., Acotto, J., Brianchon, G., Portier, G., Botez, R.M., Mamou, M., \& Mebarki, Y., (2016) "Optimization and Design of a Morphing Aircraft Wing Tip Demonstrator for Drag Reduction at Low Speed, Part I - Aerodynamic Optimization Using 3 Algorithms: Genetic, Bee Colony and Gradient Descent", This article was accepted for publication in The Chinese Journal of Aeronautics

${ }^{38}$ F.R. Menter, (1994) “Two-Equation Eddy-Viscosity Turbulence Models for Engineering Applications", AIAA Journal, Vol. 32, No.8, pp. 1598-1605.

${ }^{39}$ R.B. Langtry \& F.R. Menter, (2009) "Correlation-Based Transition Modeling for Unstructured Parallelized Computational Fluid Dynamics Codes”, AIAA Journal, Vol. 47, No. 12, pp. 2894-2906.

${ }^{40}$ ANSYS FLUENT, www.ansys.com.

${ }^{41}$ M. Drela, (1989) "XFOIL: an analysis and design system for low Reynolds number airfoils", Low Reynolds number aerodynamics, Springer.

${ }^{42}$ Koreanschi, A., Sugar, O., \& Botez, R. M. (2015) "Drag Optimization of a Wing Equipped with a Morphing Upper Surface", Royal Aeronautical Journal, March 2016, Vol. 120, No. 1225, pp.473-493, doi: 10.1017/aer.2016.6

${ }^{43}$ A. Koreanschi, O. Sugar Gabor \& R. M. Botez, (2014) "New Numerical Study of Boundary Layer Behaviour on A Morphing Wing-with-Aileron System", American Institute of Aeronautics and Astronautics AIAA 32nd Applied Aerodynamics Conference, Atlanta, GA, USA, 16-20 June.

${ }^{44}$ Mebarki, Y., Mamou, M., \& Genest, M. (2009), "Infrared Measurements of the Transition Detection on the CRIAQ Project Morphing Wing Model" NRC LTR AL-2009-0075 